ARTICLE

DOI: $10.1038 / \mathrm{s} 41467-018-04454-8$

\title{
Synthetic cytokine receptors transmit biological signals using artificial ligands
}

Erika Engelowski ${ }^{1}$, Artur Schneider ${ }^{1}$, Manuel Franke ${ }^{1}$, Haifeng $\mathrm{Xu}^{2}$, Ramona Clemen ${ }^{1}$, Alexander Lang ${ }^{1}$, Paul Baran ${ }^{1}$, Christian Binsch ${ }^{3}$, Birgit Knebel ${ }^{3}$, Hadi Al-Hasani ${ }^{3,4}$, Jens M. Moll', Doreen M. Floß1, Philipp A. Lang ${ }^{2} \&$ Jürgen Scheller ${ }^{1}$

Cytokine-induced signal transduction is executed by natural biological switches, which among many others control immune-related processes. Here, we show that synthetic cytokine receptors (SyCyRs) can induce cytokine signaling using non-physiological ligands. Highaffinity GFP- and mCherry-nanobodies were fused to transmembrane and intracellular domains of the IL-6/IL-11 and IL-23 cytokine receptors gp130 and IL-12R $\beta 1 / I L-23 R$, respectively. Homo- and heterodimeric GFP:mCherry fusion proteins as synthetic cytokine-like ligands were able to induce canonical signaling in vitro and in vivo. Using SyCyR ligands, we show that IL-23 receptor homodimerization results in its activation and IL-23-like signal transduction. Moreover, trimeric receptor assembly induces trans-phosphorylation among cytokine receptors with associated Janus kinases. The SyCyR technology allows biochemical analyses of transmembrane receptor signaling in vitro and in vivo, cell-specific activation through SyCyR ligands using transgenic animals and possible therapeutic regimes involving non-physiological targets during immunotherapy.

\footnotetext{
${ }^{1}$ Institute of Biochemistry and Molecular Biology II, Medical Faculty, Heinrich-Heine-University, 40225 Düsseldorf, Germany. ${ }^{2}$ Institute of Molecular Medicine II, Medical Faculty, Heinrich-Heine-University, 40225 Düsseldorf, Germany. ${ }^{3}$ Institute for Clinical Biochemistry and Pathobiochemistry, German Diabetes Center, Medical Faculty, Heinrich-Heine-University, 40225 Düsseldorf, Germany. ${ }^{4}$ German Center for Diabetes Research, 85764 MünchenNeuherberg, Germany. These authors contributed equally: Erika Engelowski, Artur Schneider, Manuel Franke. Correspondence and requests for materials should be addressed to J.S. (email: jscheller@uni-duesseldorf.de)
} 
S ynthetic biology deconstructs and reassembles biological bits and pieces to construct biological devices for applications such as biological sensors, releasers, and switches ${ }^{1}$. Cytokine-induced signal transduction is executed by natural biological switches among many other functions control immune-related processes ${ }^{2}$. In principle, cytokine receptors are in an off-state in the absence of cytokines and in an on-state in the presence of cytokines. The on-state might be interrupted by negative feedback mechanisms or depletion of the cytokine and cytokine receptor. In the past, we reported ligand-independent synthetic receptors based on fusions of leucine zippers or IL-15/ sushi and the IL-6-signal transducer gp130, which are locked in the on-state, but were not switchable ${ }^{3,4}$. Interestingly, a marked activation of IL-6/IL-11 signaling in inflammatory hepatocellular adenomas was directly caused by gain-of-function mutations within the gp130-receptor chain, leading to ligandindependent constitutively active gp130 receptors ${ }^{5}$. Others described switchable synthetic cytokine receptors, resulting in gp130-induced signaling by stimulation with the cytokine erythropoietin $(\mathrm{EPO})^{6}$. The major drawback of this system was that EPO has cross-reactivity with its natural EPO-receptors limiting its applications both in vitro and in vivo. Also, higher ordered multi-receptor complexes cannot be assembled using natural ligands such as EPO, which only induces receptorhomodimerization. Direct intracellular activation of signal transduction and induction of cell death was achieved using cell permeable, synthetic ligands (FK506), and binding proteins (FKBP12) resulting in homodimerization and homooligomerization $^{7,8}$. The extent of oligomerization was, however, not controllable. Various formats of synthetic transmembrane receptors have been designed to optimize engineered chimeric antigen receptor (CAR) T-cell responses, including costimulatory receptors ${ }^{9-11}$, notch-based receptors ${ }^{12}$, and antigen-specific inhibitory receptors ${ }^{13}$. However, a switchable and background-free synthetic cytokine receptor system with full control over the assembly modus of the receptor complexes, e.g., hetero/homodimeric, -trimeric, or -multimeric is not available. Such a specific system would be a valuable tool to study receptor activation, their kinetics, stoichiometry, and biochemical properties. Moreover, background-free activation of cytokine receptors opens a great potential for novel therapeutic regimes involving non-physiological ligands during immunotherapy. Recently developed nanobodies specifically recognizing GFP and mCherry fail to bind endogenous ligands $^{14}, 15$ and thus qualify as binding partners of synthetic cytokine receptors. The N-terminal region of Camelidae heavychain antibodies contains a dedicated variable domain, referred to as $\mathrm{VHH}$ or nanobodies, which binds to its cognate antigen. Nanobodies are single-domain antibodies of about 110 aminoacid residues generated from the variable regions of these heavy-chain antibodies ${ }^{16}$. Here, these nanobodies were used as extracellular sensors for homo- and heteromeric GFP:mCherry fusion proteins as part of Synthetic Cytokine Receptors (SyCyRs), ultimately leading to the formation and activation of homo- and heterodimeric and heterotrimeric receptor complexes. As biological read-out system, we use IL-23- and IL-6/ IL-11-signaling. Consequently, the extracellular sensors were fused to intracellular IL-23- and gp130-receptor chains. Using this set-up, we design a switchable synthetic cytokine receptor system, which resembles IL-23- and IL-6/IL-11-signaling and reveal that homodimeric IL-23R were biologically active. Moreover, we demonstrate that the Janus kinase activity and STAT3 phosphorylation-binding site in the intracellular domain (ICD) of the receptor can be separated on two different receptor chains, a phenomenon, which is referred to as transphosphorylation.

\section{Results}

SyCyRs simulate IL-23 and IL-6/IL-11 signaling. Natural biological switches regulate cytokine-induced signal transduction via receptor activation and inactivation. Highly specific nanobodies against GFP and mCherry were selected to mediate sensitive and background-free cytokine-like signaling. Naturally, IL-23 signals via its receptor complex consisting of IL-23R and IL-12R $\beta 1$. To mimic IL-23 signaling, we generated two synthetic cytokine receptors (SyCyRs) in which the extracellular part, including the ligand-binding site of the IL-23R and the IL-12R $\beta 1$ was replaced by nanobodies specifically recognizing mCherry $\left(\mathrm{C}_{\mathrm{VHH}}\right)$ and $\mathrm{GFP}$ $\left(\mathrm{G}_{\mathrm{VHH}}\right)$, respectively ${ }^{14,15}$ (Fig. 1a and Supplementary Fig. 1a). SyCyRs were expressed in Ba/F3-gp130 cells (Supplementary Fig. 1b), which proliferate following STAT3 activation by the fusion protein of IL-6 and soluble IL-6R named Hyper-IL-6 (HIL$6)^{17}$ (Fig. 1b). As synthetic ligands for SyCyRs, we generated GFP-mCherry fusion proteins and various combinations (Fig. 1a and Supplementary Figs. 2 and 3). Since STAT3 activation is a hallmark of IL-23 signal transduction, we tested if STAT3dependent proliferation of $\mathrm{Ba} / \mathrm{F} 3$-gp130 cells expressing $\mathrm{C}_{\mathrm{VHH}^{-}}$ IL-23R and $\mathrm{G}_{\mathrm{VHH}}-\mathrm{IL}-12 \mathrm{R} \beta 1(\mathrm{Ba} / \mathrm{F} 3-\mathrm{SyCyR}(\mathrm{IL}-23 / 2 \mathrm{~A})$ generated using 2A-technology with both cDNAs combined in one open reading frame and $\mathrm{Ba} / \mathrm{F} 3-\mathrm{SyCyR}$ (IL-23) generated with two separate cDNAs could be induced with GFP and mCherry proteins and fusions of these. Interestingly, proliferation of $\mathrm{Ba} / \mathrm{F} 3$ SyCyR(IL-23/2A) cells was specifically induced by GFP-mCherry and $2 \mathrm{xGFP}$-mCherry fusion proteins, but not by single GFP and mCherry proteins (Fig. 1b). Ba/F3 cells only expressing $\mathrm{C}_{\mathrm{VHH}^{-}} \mathrm{IL}^{\mathrm{IL}}$ $23 \mathrm{R}$ or $\mathrm{G}_{\mathrm{VHH}}$-IL-12R $\beta 1$ failed to proliferate, demonstrating the high selectivity of GFP-mCherry as a synthetic cytokine ligand. Comparative analysis of the dose-dependent proliferation of $\mathrm{Ba} /$ F3-SyCyR(IL-23/2A) and Ba/F3-IL-12R $\beta 1-I L-23 R$ cells with GFP-mCherry and Hyper-IL-23 (HIL-23), respectively, revealed that the natural cytokine and synthetic cytokine exhibited comparable potency with half-maximal proliferation achieved with HIL-23 $(56 \mathrm{kDa})$ and GFP-mCherry $(57 \mathrm{kDa})$ concentrations of about 5-10 ng/ml (Fig. 1c). GFP-mCherry-induced cellular proliferation of $\mathrm{Ba} / \mathrm{F} 3-\mathrm{SyCyR}(\mathrm{IL}-23 / 2 \mathrm{~A})$ cells was specifically inhibited by a soluble $\mathrm{G}_{\mathrm{VHH}}-\mathrm{C}_{\mathrm{VHH}}$ fusion protein (Fig. $1 \mathrm{~d}$ and Supplementary Fig. 4). Analysis of intracellular signal transduction showed that the GFP-mCherry, 2xGFP-mCherry fusion proteins, but not single mCherry, GFP and $3 \times$ GFP proteins induced JAK, STAT3, ERK1/2, and AKT phosphorylation in $\mathrm{Ba} /$ F3-SyCyR(IL-23/2A) cells (Fig. 1e, f). SyCyR(IL-23/2A) also resulted in specific STAT3 activation in U4C cells (Fig. 1g). Kinetics of pSTAT3 and SOCS3 induction following of Ba/F3SyCyR(IL-23/2A) and Ba/F3-IL-12R $\beta 1$-IL-23R cells with either GFP-mCherry or HIL-23 were comparable (Fig. 2). Since the IL$23 \mathrm{R}$ complex is not targeted by SOCS3, activation resulted in sustained STAT3 phosphorylation ${ }^{18}$. Next, we analyzed the mRNA-expression by gene-array analysis of Ba/F3-SyCyR(IL-23/ 2A) cells stimulated with GFP-mCherry and Ba/F3-IL-12R $\beta 1$-IL23R cells stimulated with HIL-23. GFP-mCherry and HIL-23 upor downregulated 107 and 193 genes, respectively, by a factor 1.5 or more (Fig. 3a). Among them are typical STAT3-target genes, including PIM1, SOCS3 and OSM (Fig. 3b, c). Pathway analysis revealed that the genes regulated by GFP-mCherry and HIL-23 belong to the same pathways (Fig. 3d and Supplementary Figs. 57). Our data revealed a high degree of overlap between the transcriptome induced by the synthetic ligand as compared to the natural cytokine.

To investigate whether SyCyRs can be activated by homodimeric ligands, we adapted this system to the IL-6/IL-11 receptor complex ${ }^{19}$. A SyCyR for gp130 was generated in which the extracellular part of the cytokine receptor was replaced by $\mathrm{G}_{\mathrm{VHH}}$ $\left(\mathrm{G}_{\mathrm{VHH}^{-}}{ }^{-g p 130)}\right.$ (Fig. 4a and Supplementary Fig. 1a). Expression of 
$\mathrm{G}_{\mathrm{VHH}^{-}}{ }^{-g p 130}$ in $\mathrm{Ba} / \mathrm{F} 3$-gp130 cells (Ba/F3-SyCyR(IL-6)) was verified by flow cytometry (Supplementary Fig. 1b). As expected, JAK, TYK, STAT3, ERK1/2 phosphorylation in Ba/F3-SyCyR(IL6) cells was specifically induced by $2 x G F P-m$ Cherry and $3 x G F P$ (Fig. 4b, c). Comparison of the dose-dependent proliferation of $\mathrm{Ba} / \mathrm{F} 3-\mathrm{SyCyR}(\mathrm{IL}-6)$ and Ba/F3-gp130 with 3xGFP and HIL-6, respectively, showed that the natural and synthetic cytokine exhibited similar activity with half-maximal proliferation at 1-10 ng/ml 3xGFP (86 kDa) or HIL-6 $(60 \mathrm{kDa})$, respectively (Fig. $4 \mathrm{~d})$.
As depicted in Fig. 4e, 3xGFP-stimulation of Ba/F3-SyCyR(IL-6) cells resulted in time-dependent fast activation and slight inactivation of STAT3 phosphorylation after $120 \mathrm{~min}$, which was accompanied by upregulation of SOCS3. Overall, 3xGFPinduced signal transduction was undistinguishable from HIL-6 induced STAT3 phosphorylation and SOCS3 expression. Next, we expressed SyCyR(IL-6) in liver tissue of C57BL/6 mice. Twenty-four hours after injection of cDNAs coding for $\mathrm{GVHH}^{-}$ gp130 and 3xGFP alone or in combination, we observed STAT3 a

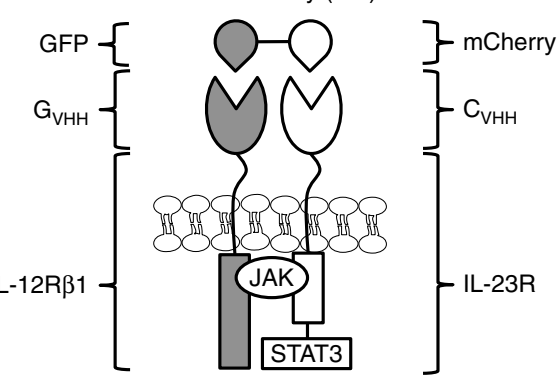

$\underbrace{G_{V H H^{-I L-12 R} \beta 1} \quad C_{V H H^{-I L-23 R}}}_{\text {SyCyR(IL-23)/SyCyR(IL-23/2A) }}$

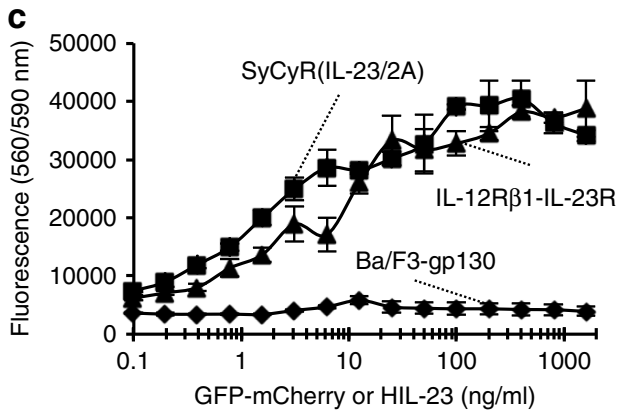

e
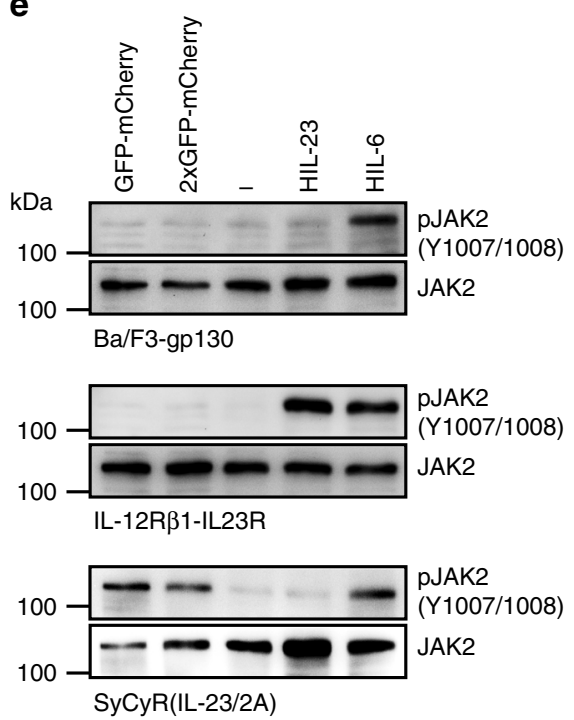

b

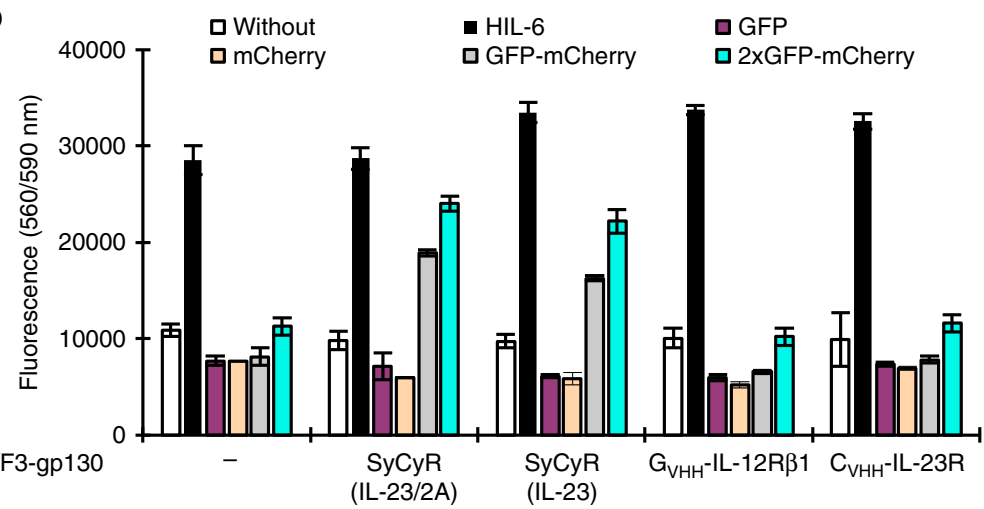

d

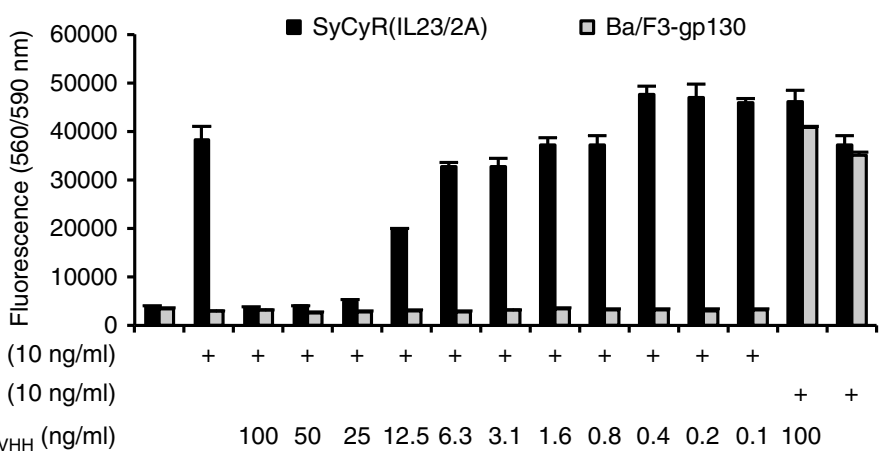

f

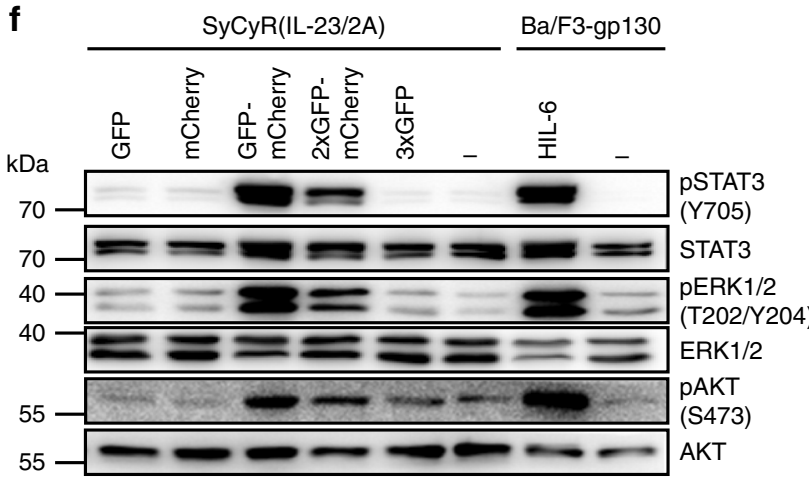

g
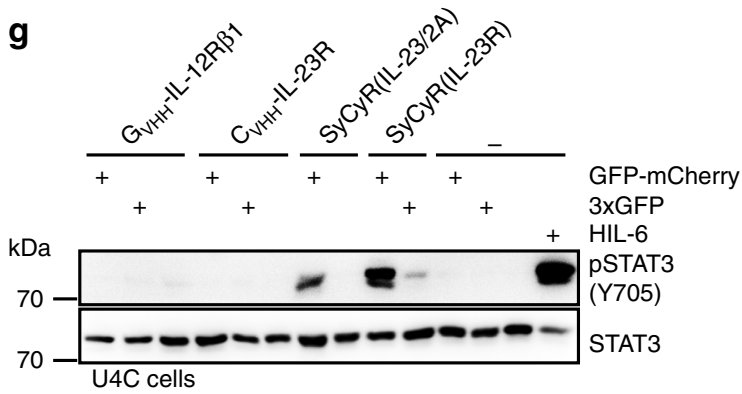
phosphorylation when $\mathrm{G}_{\mathrm{VHH}}{ }^{-\mathrm{gp} 130}$ was coexpressed with 3xGFP (Fig. 4f, g). Interestingly, $\mathrm{G}_{\mathrm{VHH}^{-}}$gp130 expression was found to be much higher in mice injected only with the cDNA coding for $\mathrm{G}_{\mathrm{VHH}}{ }^{-g p} 130$ as compared to mice expressing both, $\mathrm{G}_{\mathrm{VHH}}{ }^{-\mathrm{gp} 130}$ and $3 \times$ GFP. The data suggest that co-expression of $\mathrm{G}_{\mathrm{VHH}}-\mathrm{gp} 130$ and $3 \times$ GFP resulted in activation-dependent degradation of $\mathrm{G}_{\mathrm{VHH}}{ }^{-g p 130}$. Moreover, detection of 3xGFP in serum samples by western blotting showed strong accumulation of $3 \times$ GFP in mice injected only with the cDNA coding for $3 x G F P$, whereas $3 \mathrm{xGFP}$ was hardly detectable in mice injected with cDNAs coding for $\mathrm{G}_{\mathrm{VHH}}$-gp130 and 3xGFP. These findings suggest that not only $\mathrm{G}_{\mathrm{VHH}}{ }^{-\mathrm{gp} 130}$ but also 3xGFP protein was efficiently internalized and degraded in liver cells after binding and activation of $\mathrm{G}_{\mathrm{VHH}^{-}}$ gp130 (Fig. 4f). Consistently, expression of the acute phase response gene Saa1 was increased following injection of cDNAs coding for $\mathrm{G}_{\mathrm{VHH}}$-gp130 and 3xGFP (Fig. 4h), in sharp contrast to injection of cDNA coding for $\mathrm{G}_{\mathrm{VHH}}$-gp130 or 3xGFP alone. Overall, our data showed that the tested SyCyRs phenocopied IL6 and IL-23 signaling in vitro and in vivo.

IL-23R-SyCyR homodimers are biologically active. Since multimeric GFP was able to induce IL-6 signal transduction via homodimeric $\mathrm{G}_{\mathrm{VHH}}$-gp130, we wondered, whether IL-23R is also biologically active as a homodimer. Accordingly, we created a SyCyR consisting of the extracellular $\mathrm{G}_{\mathrm{VHH}}$ fused to the transmembrane and intracellular domains of the IL-23R $\left(\mathrm{G}_{\mathrm{VHH}}-\mathrm{IL}-\right.$ 23R; (SyCyR(IL-23R)) (Fig. 5a and Supplementary Fig. 1). Interestingly, $3 \mathrm{xGFP}$ and $2 \mathrm{xGFP}-\mathrm{mCherry}$ fusion proteins induced proliferation of $\mathrm{Ba} / \mathrm{F} 3-\mathrm{SyCyR}(\mathrm{IL}-23 \mathrm{R}$ ) cells (Fig. 5b), whereas single GFP and mCherry or the heterodimeric GFPmCherry fusion protein did not (Fig. 5b). Half-maximal proliferation was achieved at about $10-20 \mathrm{ng} / \mathrm{ml} 3 \mathrm{xGFP}(86 \mathrm{kDa})$ (Fig. 5c), which was only slightly lower as compared to Ba/F3-IL12R $\beta 1-I L-23 R$ cells stimulated with HIL-23 (56 kDa; 5-10 ng/ml). Thus, the slightly reduced activity cannot be explained through differences in the molar concentrations of the molecules. As expected, $3 \mathrm{xGFP}$ and $2 \mathrm{xGFP}$-mCherry fusion proteins but not single GFP induced JAK, STAT3, pERK1/2, and AKT phosphorylation in $\mathrm{Ba} / \mathrm{F} 3-\mathrm{SyCyR}(\mathrm{IL}-23 \mathrm{R}$ ) cells (Fig. 5d, e). Also the kinetics of pSTAT3 activation and SOCS3 expression of HIL-23 and $3 \times$ GFP were comparable (Figs. $5 f$ and $2 \mathrm{f}$ ), suggesting that also IL-23R homodimers were not negatively regulated by SOCS3. Surprisingly, only 35 genes were up- or downregulated by at least 1.5-fold after stimulation of Ba/F3-SyCyR(IL-23R) with 3xGFP. However, 34 out of 35 transcripts were also found in the GFPmCherry-group (Ba/F3-SyCyR(IL-23/2 A)) (Fig. 6a). Among the 35 regulated genes are typical IL-23 target genes, including PIM,
SOCS3, and OSM (Fig. 6b, c). Although, a reduced number of genes was triggered by homodimeric IL-23R signaling when compared to IL-12R $\beta 1$-IL-23R heterodimer stimulation, similar signaling pathways were affected (Figs. 6c, 3d and Supplementary Figs. 5-8). In conclusion, homotypic activation of SyCyR(IL-23R) also phenocopied IL-23 signaling in terms of signal transduction pathways and kinetics, but resulted in overall reduced induction of gene expression as compared to SyCyR(IL-23/2A).

Heterotrimeric SyCyRs induce STAT3 trans-phosphorylation. During trans-phosphorylation a kinase-active receptor is able to trans-phosphorylate a kinase-negative mutant receptor. Since 2xGFP-mCherry was able to induce functional hetero- and homodimerization of SyCyRs, we wondered whether 2xGFPmCherry can induce trans-phosphorylation of STAT3 via synthetic trimeric receptor complexes. Hence, a C-terminally truncated IL-23R $(\Delta 503)$, lacking the canonical STAT-binding motifs but retained JAK, ERK, and AKT activity (IL-23R- $\triangle$ STAT) was selected and fused with $\mathrm{G}_{\mathrm{VHH}}$ (Fig. $7 \mathrm{a}$ and Supplementary Fig. 9a). Janus kinases interact with peptide motifs within the IL23R localized between amino acid 403-479 and complete or partial deletion results in disabled JAK activity ${ }^{18}$. Accordingly, we created three deletion variants of the IL-23R intracellular domain with disabled JAK activity, $\triangle \mathrm{JAK}-\mathrm{A}(\Delta 403-417), \Delta \mathrm{JAK}-\mathrm{B}$ $(\Delta 455-479)$, and $\triangle$ JAK-C $(\Delta 403-479)^{20}$ fused to the mCherrynanobody (Fig. 7a and Supplementary Fig. 9a). Cell surface expression of these SyCyRs in Ba/F3-gp130 cells was verified by flow cytometry (Supplementary Fig. 9b). As expected, stimulation of $\mathrm{G}_{\mathrm{VHH}}$-IL-23R- $\Delta$ STAT in Ba/F3-gp130 cells with 2xGFPmCherry resulted in JAK and ERK phosphorylation but defective STAT3 activation (Fig. 7b, c). Consequently, 3xGFP-induced proliferation of $\mathrm{Ba} / \mathrm{F} 3-\mathrm{G}_{\mathrm{VHH}}-\mathrm{IL}-23 \mathrm{R}-\Delta \mathrm{STAT}$ cells was drastically reduced as compared to Ba/F3-SyCyR(IL-23R) cells (Fig. 7d). Interestingly, only the assembly of a $2 x G F P-m C h e r r y-i n d u c e d$ trimeric complex consisting of two $\mathrm{G}_{\mathrm{VHH}}-\mathrm{IL}-23 \mathrm{R}-\Delta \mathrm{STAT}$ receptors and one $\mathrm{C}_{\mathrm{VHH}}-\mathrm{IL}-23 \mathrm{R}-\Delta \mathrm{JAK}$ receptor resulted in increased STAT3 trans-phosphorylation and cellular proliferation (Fig. 7c, e). Dimerization of $\mathrm{G}_{\mathrm{VHH}^{-}}{ }^{-I L}-23 \mathrm{R}-\Delta \mathrm{STAT}$ with all $\mathrm{C}_{\mathrm{VHH}^{-}}$ $\triangle \mathrm{JAK}$ receptors by GFP-mCherry did not induce STAT activation, demonstrating that two biologically active JAKs in $\mathrm{G}_{\mathrm{VHH}}$-IL23R- $\triangle$ STAT were needed for STAT3 trans-phosphorylation. Of note, also stimulation with a 2 xmCherry fusion protein and formation of dimeric $\mathrm{C}_{\mathrm{VHH}}$-IL-23R- $\Delta \mathrm{JAK}$ did not result in STAT3 phosphorylation, whereas homodimers of $\mathrm{C}_{\mathrm{VHH}}-\mathrm{IL}-23 \mathrm{R}$ were biologically active (Supplementary Fig. 10), demonstrating that the $\mathrm{C}_{\mathrm{VHH}}-\mathrm{IL}-23 \mathrm{R}-\Delta \mathrm{JAK}$ variants were not biologically active as dimers.

Fig. 1 SyCyRs for IL-23 (SyCyR(IL-23/2A)) simulate IL-23-induced signal transduction. a Schematic illustration of IL-23 SyCyR and GFP-mCherry fusion

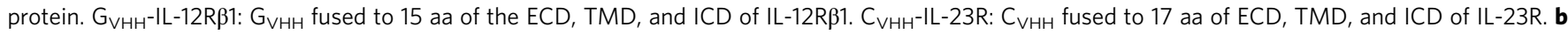
Proliferation of Ba/F3-gp130 cell lines with HIL-6 and GFP:mCherry cultured with synthetic ligands $(6.25 \mathrm{ng} / \mathrm{ml})$ or HIL-6 (10 ng/ml). Stimulation with mCherry was made with the same volume as with GFP (0.25\%). One representative experiment out of three is shown. c Proliferation of Ba/F3-SyCyR(IL23/2A) and Ba/F3-gp130 cells with GFP-mCherry and Ba/F3-IL-12R $\beta 1-I L-23 R$ cells with HIL-23 cultured in the presence of ligands (0.1 to $1600 \mathrm{ng} / \mathrm{ml}$ ). One representative experiment out of five is shown. $\mathbf{d}$ Proliferation of Ba/F3-SyCyR(IL-23/2A) and Ba/F3-gp130 cells with GFP-mCherry fusion protein in the presence of $\mathrm{G}_{\mathrm{VHH}}-\mathrm{C}_{\mathrm{VHH}}$. Cells were cultured in the presence of GFP-mCherry $(\mathrm{GC} ; 10 \mathrm{ng} / \mathrm{ml})$ and increasing concentrations of $\mathrm{G}_{\mathrm{VHH}}-\mathrm{C}_{\mathrm{VHH}}(0.1-100$ $\mathrm{ng} / \mathrm{ml}$ ). One representative experiment out of four is shown. Results in $\mathbf{b}, \mathbf{c}$, and $\mathbf{d}$ are mean \pm s.d. of three replicates. e JAK activation in Ba/F3-gp130, Ba/ F3-IL-12Rß1-IL-23R, and Ba/F3-SyCyR(IL-23/2A) cells stimulated with $100 \mathrm{ng} / \mathrm{ml}$ of indicated synthetic ligands or HIL-6 (100 ng/ml) for $20 \mathrm{~min}$. Equal amounts of total protein $(50 \mu \mathrm{g} /$ lane $)$ were analyzed using specific antibodies for phospho-JAK2 and JAK2. Western blot data show one representative experiment out of three. f STAT3, ERK1/2, and AKT activation in Ba/F3-SyCyR(IL-23/2A) and Ba/F3-gp130 cells treated with $100 \mathrm{ng} / \mathrm{ml}$ of the indicated ligands or HIL-6 $(10 \mathrm{ng} / \mathrm{ml})$ for $30 \mathrm{~min}$. Stimulation with mCherry was made with the same volume as with GFP (2\%). Equal amounts of total protein (50 $\mu \mathrm{g} /$ lane) were analyzed using specific antibodies for phospho-STAT3/ERK1/2/AKT and STAT3/ERK1/2/AKT. Western blot data show one representative experiment out of three. $\mathbf{g}$ STAT3 activation in U4C cells expressing SyCyR receptors were stimulated with $100 \mathrm{ng} / \mathrm{ml}$ of the indicated synthetic ligands or HIL-6 (10 ng/ml) for $60 \mathrm{~min}$. Equal amounts of total protein $(25 \mu \mathrm{g} /$ lane for HIL- 6 and $50 \mu \mathrm{g} /$ lane for other ligands) were analyzed using specific antibodies for phospho-STAT3 and STAT3. Western blot data show one representative experiment out of two 
a

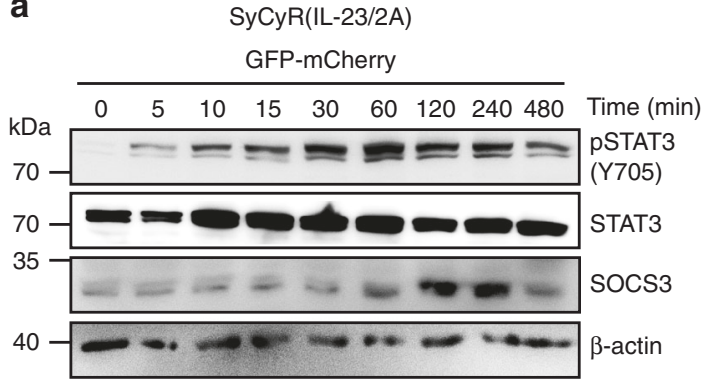

HIL-23

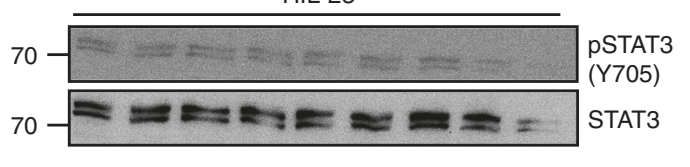

HIL-6

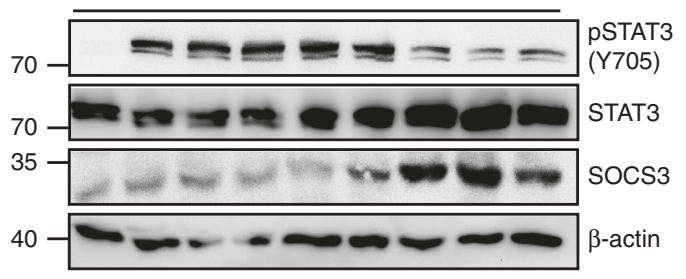

b
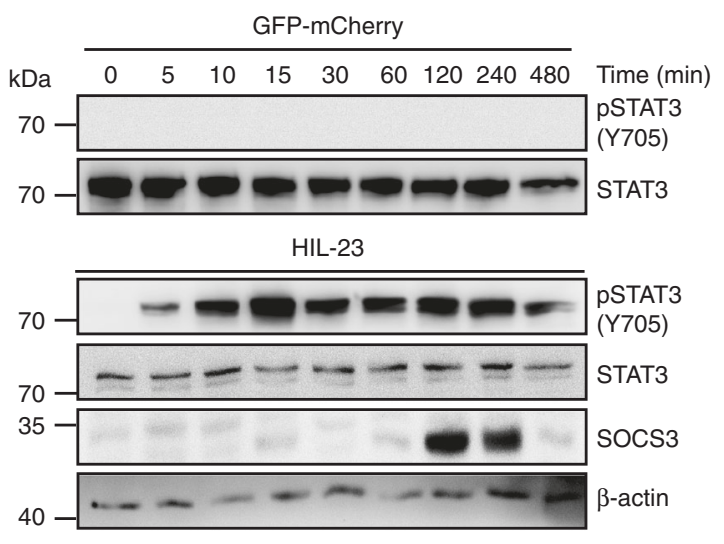

HIL-6

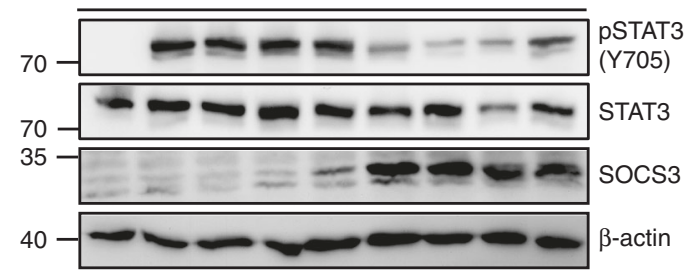

Fig. 2 Synthetic cytokine receptors for IL-23 (SyCyR(IL-23/2A)) simulate kinetics of IL-23-induced STAT3 activation and SOCS expression in transduced $\mathrm{Ba} / \mathrm{F3}$-gp130 cells. a Ba/F3-SyCyR(IL-23/2A) cells were washed three times, starved, and stimulated with GFP-mCherry (100 ng/ml), HIL-23 (25 ng/ml), and HIL-6 $(25 \mathrm{ng} / \mathrm{ml})$ for 0-480 min. Stimulation with HIL-23 and HIL-6 were used as control. Cellular lysates were prepared, and equal amounts of total protein $(50 \mu \mathrm{g} /$ lane $)$ were loaded on SDS gels, followed by immunoblotting using specific antibodies for phospho-STAT3 and STAT3, SOCS3, and $\beta$-actin. Western blot data show one representative experiment out of three. $\mathbf{b} \mathrm{Ba} / \mathrm{F} 3-\mathrm{IL}-12 \mathrm{R} \beta 1-\mathrm{IL}-23 \mathrm{R}$ cells were washed three times, starved, and stimulated with HIL-23 $(25 \mathrm{ng} / \mathrm{ml})$ for 0-480 min. Stimulation with GFP-mCherry $(100 \mathrm{ng} / \mathrm{ml})$ and HIL-6 $(25 \mathrm{ng} / \mathrm{ml})$ were used as control. Cellular lysates were prepared, and equal amounts of total protein ( $50 \mu \mathrm{g} /$ lane) were loaded on SDS gels, followed by immunoblotting using specific antibodies for phospho-STAT3 and STAT3, SOCS3, and $\beta$-actin. Western blot data show one representative experiment out of three

Cytokine receptors can be classified into high-affinity binders with longer ICDs and lower-affinity binders with shorter ICDs. Interestingly, high-affinity receptors with STAT-binding sites often heterodimerize with JAK1 or JAK2, whereas low-affinity receptors often pair with TYK2 or JAK3, and minimally contribute to STAT recruitment and activation ${ }^{21,22}$. Combining the short ICD- and TYK-binding-receptor $\mathrm{G}_{\mathrm{VHH}}$-IL-12R $\beta 1$ with $\mathrm{C}_{\mathrm{VHH}}$-IL-23R- $\Delta \mathrm{JAK}-\mathrm{B}$, in Ba/F3-gp130 cell lines did not result in trans-phosphorylation and proliferation (Fig. 8b, c and Supplementary Fig. 11), demonstrating that this combination fails to induce receptor activation.

Finally, we asked if the SyCyRs $\mathrm{C}_{\mathrm{VHH}^{-}} \mathrm{IL}-23 \mathrm{R}-\Delta \mathrm{JAK}-\mathrm{B}$ might be trans-phosphorylated by $\mathrm{G}_{\mathrm{VHH}}$-gp130 (SyCyR(IL-6)). We generated a C-terminally truncated gp130 $(\Delta 758)$ lacking both the STAT and ERK/AKT activation motifs ${ }^{23}$ fused to the $G_{V H H}$ (G $\mathrm{G}_{\mathrm{VH}}-\mathrm{gp} 130-\Delta \mathrm{STAT}$ ) (Fig. 8d and Supplementary Fig. 12). Ba/ F3-gp130 cells expressing $\mathrm{G}_{\mathrm{VHH}}$-gp130- $\Delta$ STAT displayed no STAT3 phosphorylation after stimulation with 2xGFP-mCherry and $3 x$ GFP (Fig. 8e). In analogy to the IL-23R- $\triangle$ STAT-SyCyRs, the combined activation of $\mathrm{G}_{\mathrm{VHH}^{-}}$gp 130- $\Delta$ STAT with $\mathrm{C}_{\mathrm{VHH}}-\mathrm{IL}-$ $23 \mathrm{R}-\triangle \mathrm{JAK}-\mathrm{B}$ resulted in STAT3 trans-phosphorylation and cellular proliferation (Fig. 8e, f).

\section{Discussion}

Here, we describe the development of a synthetic cytokine receptor system based on nanobodies directed against GFP and mCherry fused to truncated cytokine receptors. Nanobodies are versatile tools widely used in molecular biology, exhibiting highaffinity and antigen specificity. We chose nanobodies against GFP and mCherry because these fluorescent proteins are non-toxic to mammalian cells, will not cause unspecific binding to endogenous receptors and are, therefore, considered as side-effect/background-free 24,25 . As receptor system, we used heterodimeric and homodimeric cytokine receptor compositions exemplified by IL23 and IL-6 receptor signaling complexes. IL-23 signals via a heterodimeric receptor complex consisting of IL-12R $\beta 1$ and IL$23 \mathrm{R}$, whereas IL-6 signals via the non-signal-transducing IL-6R and the signal-transducing homodimer of gp $130^{19}$. Both receptor complexes induce signals via receptor-associated Janus kinases that activate STAT, ERK, and AKT pathways ${ }^{26,27}$. JAKs are constitutive but non-covalently associated with class I and II cytokine receptors, which upon cytokine binding bring together two JAKs to create an active signaling complex. JAK interact with receptor peptide motifs, which are present in the intracellular domain of cytokine receptors. During receptor activation, JAKs switch into the "on"-status by reciprocal phosphorylation and subsequent phosphorylation of receptor-tyrosines and signaling molecules such as STAT3 ${ }^{28}$.

The synthetic receptor complex mimicking IL-23-signaling was activated by a heterodimeric synthetic GFP-mCherry ligand but not by single GFP or mCherry or multimeric GFP fusion proteins, whereas the synthetic receptor complex simulating IL-6signaling was specifically activated by homodimeric synthetic GFP-ligands. Importantly, GFP-mCherry and 3xGFP fusion proteins did not activate cellular responses in cells lacking synthetic cytokine receptors.

A recent report showed that not only the intracellular domains determine the signaling strength but also the mode of extracellular receptor complex assembly ${ }^{29}$. Specifically, a point mutation in EPO was shown to change EPO receptor dimerization, which resulted in reduced STAT1 and STAT3 phosphorylation 
a

IL-12R $\beta 1-I L-23 R$ w/ vs. w/o HIL-23 (natural system)

SyCyR(IL-23/2A) w/ vs. w/o GFP-mCherry (synthetic system)

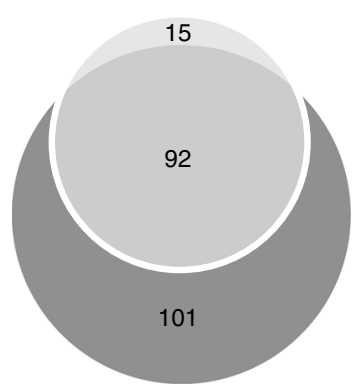

C
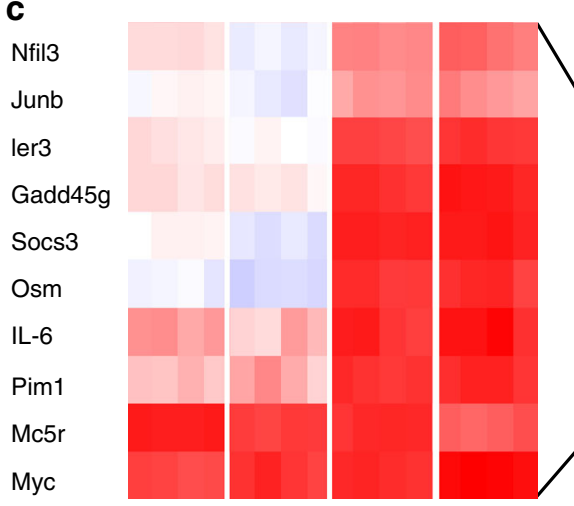

b
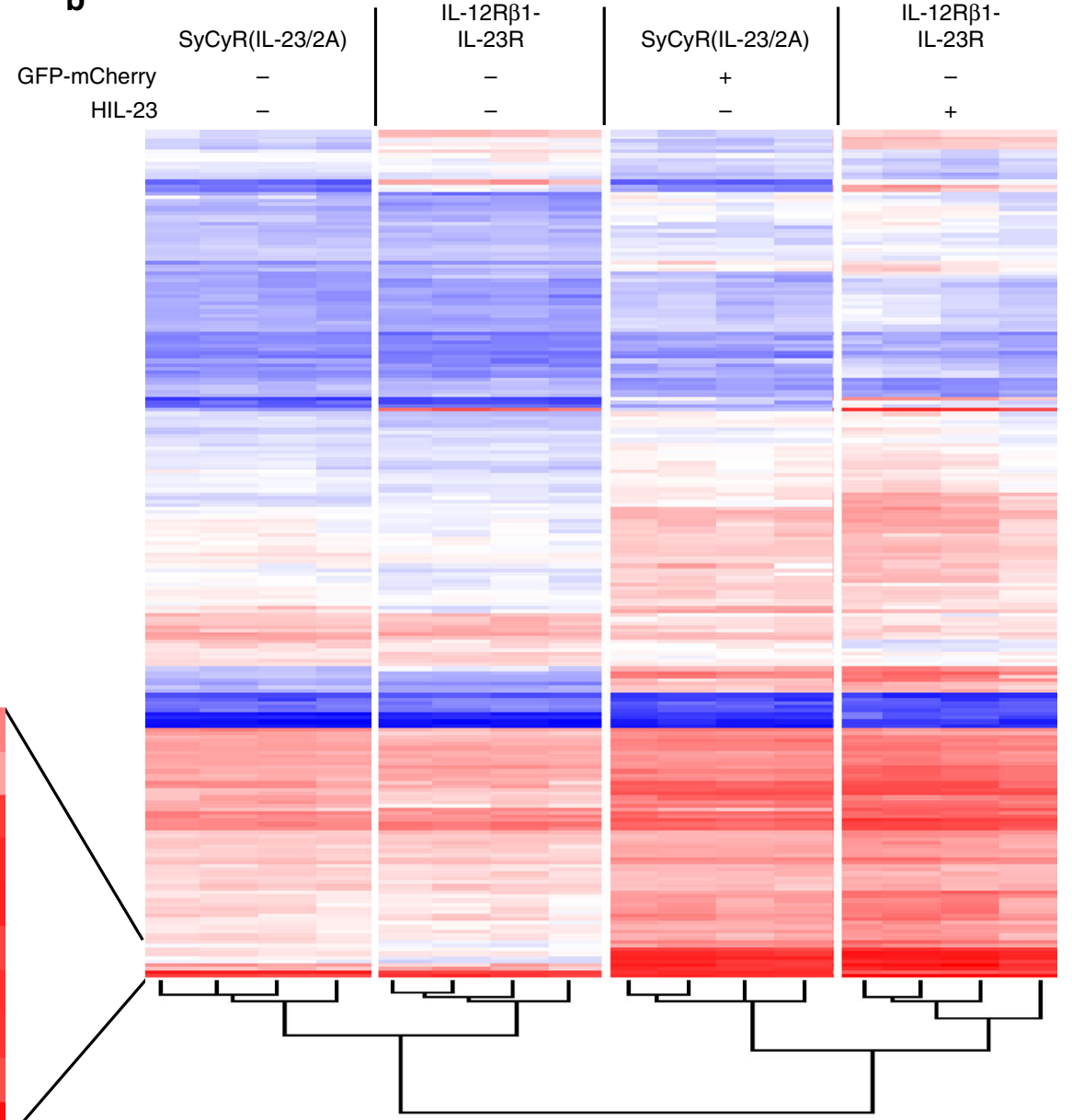

4.25 d

\begin{tabular}{|c|c|c|}
\hline Name & $P$-value & Overlap \\
\hline IL-10 signaling & $6.38 \mathrm{E}-08$ & $\begin{array}{c}11.8 \% \\
8 / 68\end{array}$ \\
\hline $\begin{array}{l}\text { Role of macrophages, } \\
\text { fibroblasts and } \\
\text { endothelial cells in } \\
\text { rheumatoid arthritis }\end{array}$ & $1.78 \mathrm{E}-07$ & $\begin{array}{l}4.5 \% \\
14 / 309\end{array}$ \\
\hline $\begin{array}{l}\text { IL-17A signaling in } \\
\text { fibroblasts }\end{array}$ & $3.00 E-07$ & $\begin{array}{c}17.1 \% \\
6 / 35\end{array}$ \\
\hline $\begin{array}{l}\text { Th1 and Th2 activation } \\
\text { pathway }\end{array}$ & $2.25 \mathrm{E}-06$ & $\begin{array}{l}5.4 \% \\
10 / 185\end{array}$ \\
\hline Jak/Stat signaling & 4.27E-06 & $\begin{array}{c}8.4 \% \\
7 / 83\end{array}$ \\
\hline
\end{tabular}

Top canonical pathways of SyCyR(IL-23/2A)

\begin{tabular}{|l|c|c|}
\hline \multicolumn{1}{|c|}{ Name } & $P$-value & Overlap \\
\hline $\begin{array}{l}\text { Role of macrophages, } \\
\text { fibroblasts and } \\
\text { endothelial cells in } \\
\text { rheumatoid arthritis }\end{array}$ & $1.93 \mathrm{E}-08$ & $3.9 \%$ \\
$12 / 309$ \\
\hline $\begin{array}{l}\text { Th1 and Th2 activation } \\
\text { pathway }\end{array}$ & $1.91 \mathrm{E}-07$ & $4.9 \%$ \\
\hline Th1 pathway & $2.10 \mathrm{E}-07$ & $9 / 185$ \\
\hline IL-17A signaling in & & $5.9 \%$ \\
\hline fibroblasts & $5.48 \mathrm{E}-07$ & $14.3 \%$ \\
\hline IL-10 signaling & & $5 / 35$ \\
\hline
\end{tabular}

Fig. 3 Microarray analysis of Ba/F3-SyCyR(IL-23/2 A) cells. a Venn-diagram of at least 1.5-fold ( $p$-value $\leq 0.01$ ) up- or downregulated mRNAs of Ba/F3SyCyR(IL-23/2A) cells stimulated with $100 \mathrm{ng} / \mathrm{ml}$ GFP-mCherry (light gray) and Ba/F3-IL-12Rß1-IL-23R cells stimulated with $100 \mathrm{ng} / \mathrm{ml} \mathrm{HIL-23} \mathrm{(dark}$ gray) for $60 \mathrm{~min}$. Microarray analysis was performed using samples of four independent biological replicates. $\mathbf{b}$ Heat map comparing mRNA levels of Ba/ F3-SyCyR(IL-23/2A) and Ba/F3-IL-12Rß1-IL-23R stimulated and unstimulated as described in a. c Higher magnification of selected mRNAs from b. d Ingenuity pathway analysis (IPA) revealed the top five canonical pathways of Ba/F3-SyCyR(IL-23/2A) vs. Ba/F3-IL-12RB1-IL-23R 
but did not affect STAT5 activation ${ }^{29}$. This implies, that replacing the extracellular part of a cytokine receptor by another binding domain, such as nanobodies might influence signaling strength and kinetics, which ultimately lead to an altered intracellular response of the chimeric receptor. To exclude such effects for our synthetic cytokine receptors, apart from general analysis of typical signal transduction pathways (JAK/STAT, ERK, AKT), we verified that the time-dependent activation profile of IL-23 and IL-6 is identical with those of synthetic ligands. These findings were supported by transcriptome comparison of Ba/F3-IL-23RIL-12R $\beta 1$ and $\mathrm{Ba} / \mathrm{F} 3-$ SyCyR(IL-23/2A) cells, activated by HIL-23 and GFP-mCherry, respectively, in which almost all regulated genes for both cytokines were identical. Even though more regulated genes were detected after HIL-23 stimulation as a

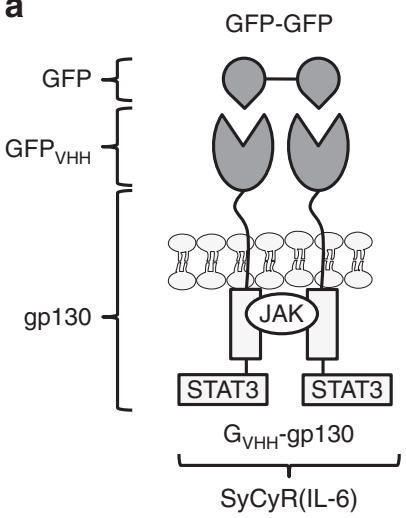

b

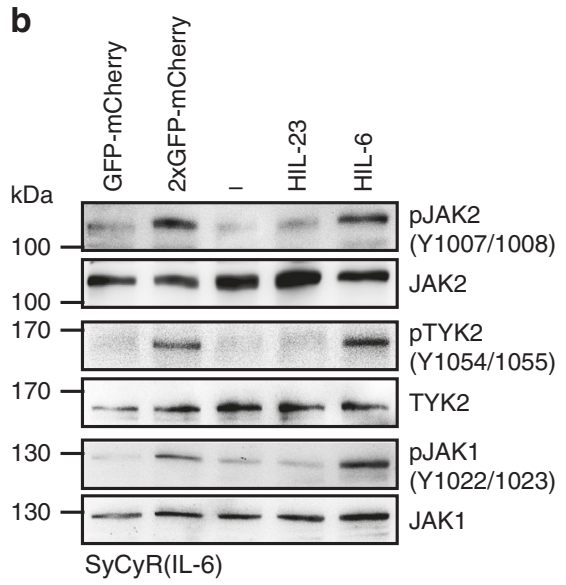

c

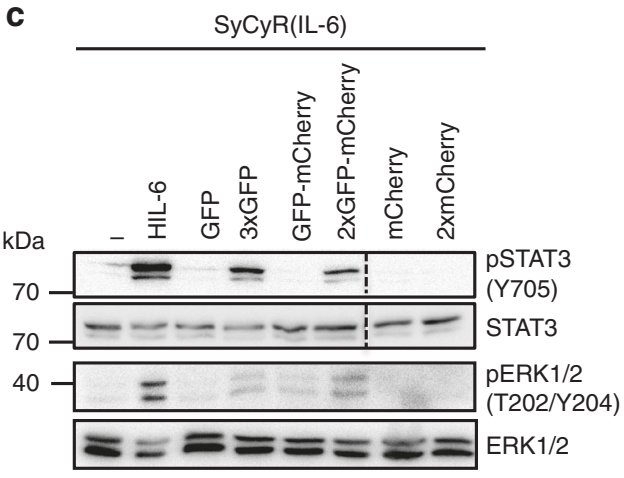

d

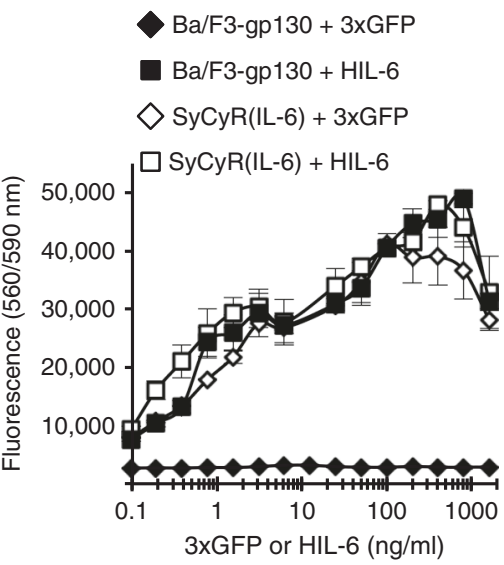

e

SyCyR(IL-6)

SyCyR(IL-6)

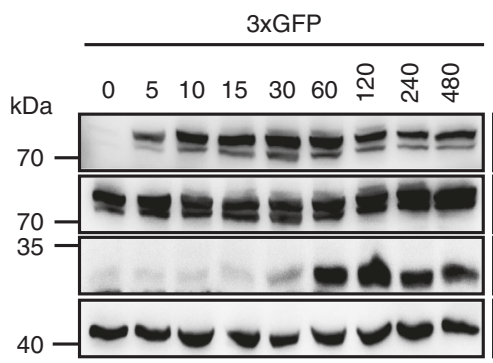

HIL -6

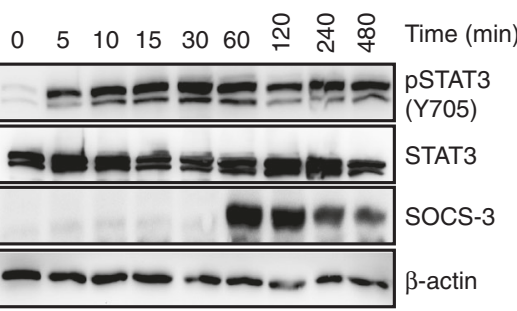

f

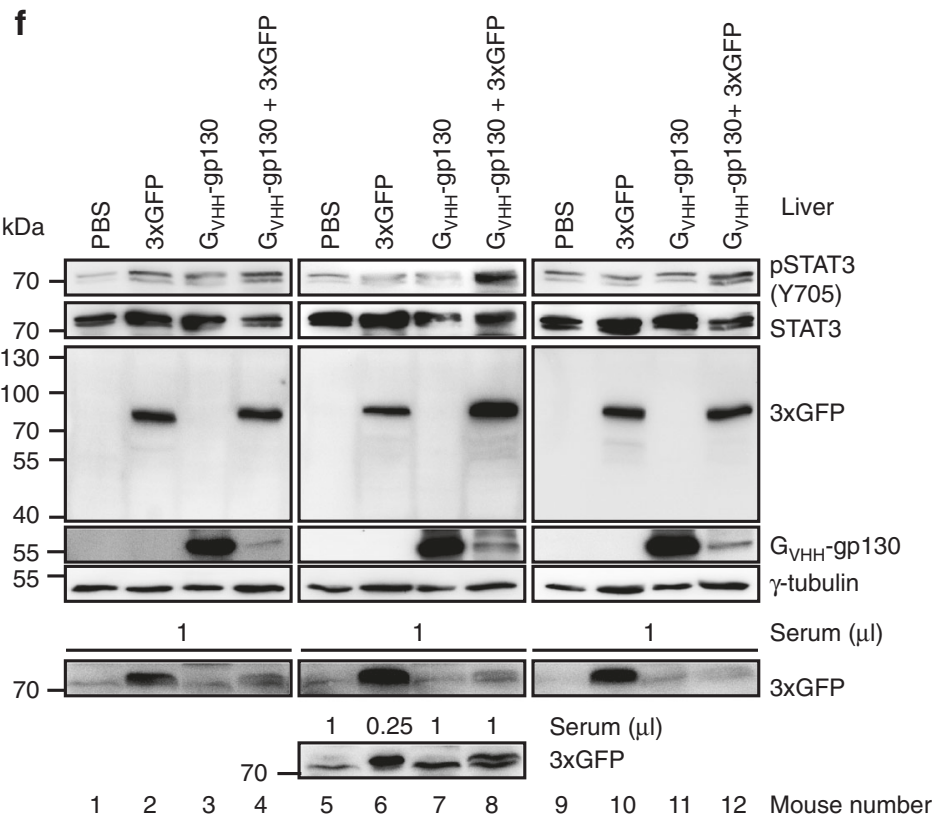

g

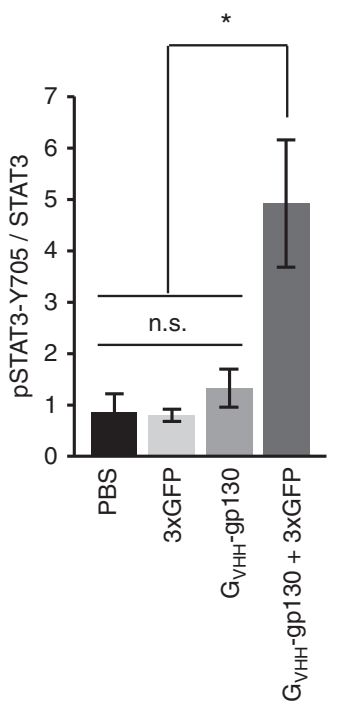

h

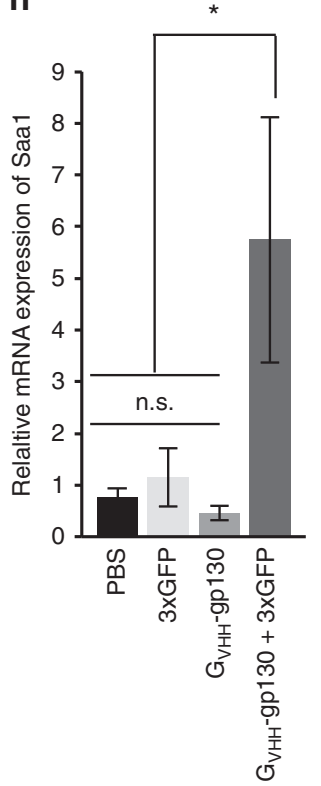


compared to GFP-mCherry stimulation, this difference was within expected fluctuations when using cell lines, which have been transduced with different receptor complexes and have been independently selected and cultivated for several weeks. Importantly, pathway analysis of the natural and synthetic IL-23 receptor complexes highlighted that naturally and synthetically induced signal transduction was basically identical. To the best of our knowledge, this is the first study using chimeric receptor complexes, which included a detailed analysis of signal transduction pathways and expression profiles. Importantly, the synthetic receptors appear to be active in vivo, since we demonstrated the activation of $\mathrm{G}_{\mathrm{VHH}^{-}}$-gp 130 by $3 \mathrm{xGFP}$ in the liver of mice after hydrodynamic injection.

So far, no signaling role of IL-12R $\beta 1$ in the receptor complex apart from activation of a Janus kinase has been assigned ${ }^{20}$. Consistently, using our synthetic receptors, we induced IL-23R homodimeric receptor complexes, as we have recently suggested $^{30}, 31$. Although the general activation of signaling pathways appeared to be similar to IL-23 signaling, gene-array analysis revealed a reduced number of regulated genes when compared to heterodimeric signaling. This phenomenon could be caused by the slightly reduced proliferation observed following SyCyR(IL-23R) signaling when compared to natural IL-23R/IL$12 \mathrm{R} \beta 1$ complex. Moreover, reduced affinity or biochemical features of the synthetic ligand may affect SyCyR signaling. This effect might also contribute to the observation, that the natural and synthetic IL-23 receptor activation was different in terms of the absolute number of regulated genes.

The modular nature of the synthetic ligands, with one receptor binding site per GFP or mCherry allows an exact composition of the receptor stoichiometry, which clearly will be interesting for many if not all other cytokine receptors. Moreover, this system will enable the combinatory assembly of uncommon receptor combinations with desirable signaling potentials and capacities. The number of recruited synthetic receptors is only limited by the maximal number of ligands connected in one GFP:mCherry fusion protein or by alternative $\mathrm{GFP} / \mathrm{mCherry}$ multimerization strategies $^{32,33}$.

Two recent reports describe surrogate dimeric ligands, which specifically bind and activate natural cytokine receptors supporting our hypothesis that receptor activation might be generally possible by dimeric ligands ${ }^{34,35}$. For IL- 6 and IL-23 signaling, we used homo- and heterodimeric GFP:mCherry fusion proteins, but we were also able to generate homo- and heterotrimeric GFP: mCherry variants. Using these synthetic ligands, we analyzed, if biologically active trimeric receptor complexes could also be functionally assembled among the cytokine receptor family with associated kinases. Tyrosine-receptors and receptors with associated kinases are typically active as dimers ${ }^{36}$ to juxtapose and subsequently activate at least two receptor kinases. This implies that these receptor systems naturally did not require a third receptor. To generate trimeric receptor complexes for IL-6 and IL-23-simulations, we deleted the STAT3-binding motifs in the synthetic $G_{\mathrm{VHH}}$-IL-23 and $\mathrm{G}_{\mathrm{VHH}}$-gp130 receptors and combined these receptors with JAK-deficient receptors containing STATbinding motifs fused to $\mathrm{C}_{\mathrm{VHH}}$. We showed that in these trimeric receptor combinations, STAT3 activation is mediated by transphosphorylation. The formation of a trimeric receptor complex with two JAK-proficient but STAT-deficient receptors and one STAT-binding motif receptor by GFP-GFP-mCherry (2xGFPmCherry) resulted in STAT3 trans-phosphorylation. Assembly of one JAK-proficient receptor with one STAT-binding motif receptor by a GFP-mCherry fusion did, however, not lead to trans-phosphorylation, confirming that one Janus kinase is not sufficient for receptor activation. Of note, trans-phosphorylation was thus far only described for tyrosine-kinase-receptors of the PDGF and EGF family ${ }^{37-41}$, in which a kinase-active receptor was able to trans-phosphorylate a second kinase-inactive mutant receptor after receptor dimerization. In these cases, the kinasenegative mutant receptor was able to activate the functional kinase of the other receptor. Here, we describe for the first receptor-chain trans-phosphorylation for cytokine receptors with associated Janus kinases.

In summary, the synthetic cytokine receptor system allows tailor-made activation and analysis of cytokine signaling by recruitment of defined numbers and compositions of receptor chains. Receptor assembly is determined by the number and sequence of GFP-mCherry units in the ligand fusion proteins. This system simulates signal transduction without relevant background activation that has been described previously with chimeric receptor systems ${ }^{6}$. The lack of toxicity of fluorescent proteins in vitro and in vivo allows a widespread area of potential applications for studying cell-type specific receptor activation by synthetic ligand application in transgenic mice. Importantly, our system is easily on/off-switchable, because signal activation can be rapidly inhibited by application of soluble nanobody-fusion proteins directed against the synthetic GFP:mCherry ligands and will open up therapeutic regimes involving non-physiological targets during immunotherapy.

\section{Methods}

Cells and reagents. CHO-K1 (ACC-110) cells were from Leibniz Institute DSMZ German Collection of Microorganisms and Cell Cultures (Braunschweig, Germany). U4C cells were kindly provided by Heike Hermanns (University Würzburg,

\footnotetext{
Fig. 4 SyCyRs for IL-6 (SyCyR(IL-6)) simulate IL-6/IL-11-induced signal transduction. a Schematic illustration of IL-6 SyCyR and GFP-GFP. GVHH-gp130: $\mathrm{G}_{V H H}$ fused to 13 aa of the ECD, TMD, and ICD of gp130. b JAK and TYK activation in Ba/F3-SyCyR(IL-6) cells stimulated with supernatants containing $100 \mathrm{ng} / \mathrm{ml}$ of indicated synthetic ligands or HIL-6 (100 ng/ml) for 20 min. Equal amounts of total protein (50 $\mu$ g/lane) were analyzed for phospho-JAK2/ TYK2/JAK1 and JAK2/TYK2/JAK1. Western blot data show one representative experiment out of three. c STAT3 and ERK1/2 activation in Ba/F3-SyCyR (IL-6) cells stimulated with $4 \%$ conditioned supernatant containing mCherry, $2 x m C h e r r y$ or conditioned supernatants containing $100 \mathrm{ng} / \mathrm{ml}$ of indicated synthetic ligands for $60 \mathrm{~min}$. Stimulation with HIL-6 (10 ng/ml) for $15 \mathrm{~min}$ was used as control. Equal amounts of total protein (50 $\mu \mathrm{g} /$ lane) were analyzed for phospho-STAT3/ERK1/2 and STAT3/ERK1/2. One representative experiment out of two is shown. d Proliferation of Ba/F3-SyCyR(IL-6) and Ba/F3gp130 cells with 3 XGFP and HIL-6 cultured in the presence of ligands $(0.1$ to $1600 \mathrm{ng} / \mathrm{ml})$. One representative experiment out of five is shown. Results are mean \pm s.d. of three replicates. e Ba/F3-SyCyR(IL-6) cells were stimulated with 3xGFP (100 ng/ml) and HIL-6 (25 ng/ml) for 0-480 min. Total protein (50 $\mu \mathrm{g} /$ lane) were analyzed for phospho-STAT3 and STAT3, SOCS3, and $\beta$-actin. Western blot data show one representative experiment out of three. f Western blot of mouse liver lysates and mouse serum prepared $24 \mathrm{~h}$ following hydrodynamic transfection of PBS, pcDNA3.1-3xGFP (1.28 $\mu$ g) and/or pcDNA3.1-G VHH $^{-g p 130 ~(2.3 \mu g) ~ p l a s m i d ~ D N A . ~ T o t a l ~ p r o t e i n s ~(~} 50 \mu \mathrm{g} /$ lane) were analyzed for phospho-STAT3, STAT3, GFP, and $\gamma$-tubulin. Serum volumes from $0.25-1 \mu \mathrm{l}$ were analyzed for GFP; $n=3$ animals/group. $\mathbf{g}$ Ratio of relative density of pSTAT3 and STAT3 liver expression as determined in $\mathbf{f}$; Results are mean \pm s.e.m. of three animals/group. Significance of difference (one-way ANOVA): ${ }^{\star} p<0.05$. $\mathbf{h}$ qRT-PCR of Saa1 mRNA $24 \mathrm{~h}$ after hydrodynamic transfection of $1.28 \mu \mathrm{g}$ pcDNA3.1-3xGFP and/or $2.3 \mu \mathrm{g}$ pcDNA3.1-GVHн-gp130 plasmid and normalized using the housekeeper mRNA Gapdh and the $\Delta \Delta C T$ method; Results are mean \pm s.e.m. of six animals/group. Significance of difference (one-way ANOVA): ${ }^{\star} p<0.05$
} 
a

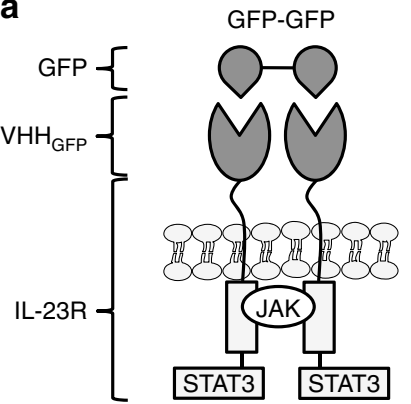

$\underbrace{G_{V H H^{-I L-23 R}}}_{\text {SyCyR(IL-23R) }}$ b

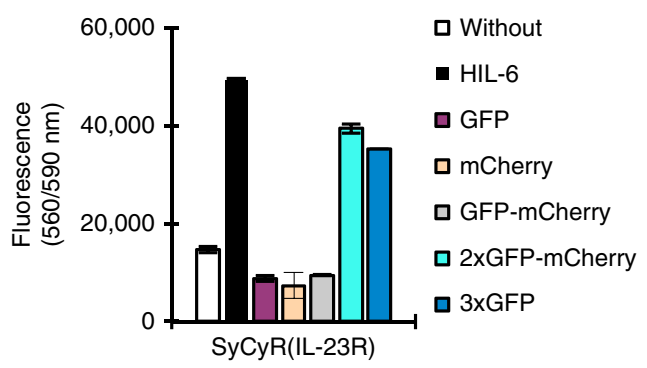

C

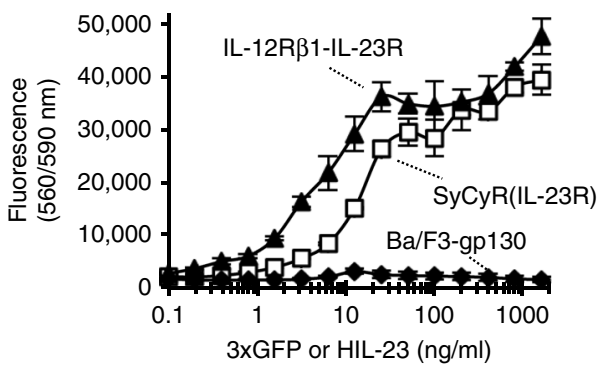

d
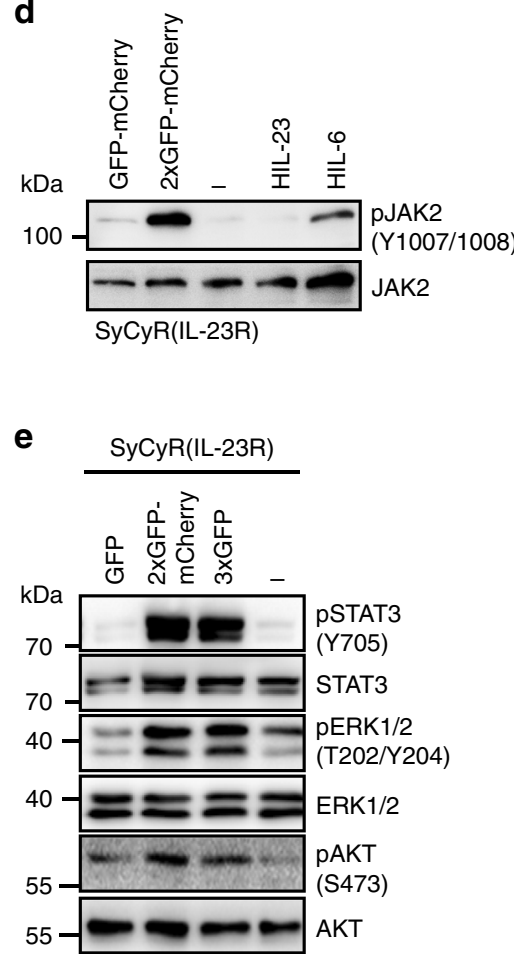

$\mathbf{f}$

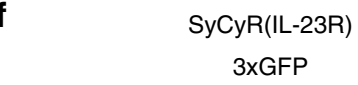

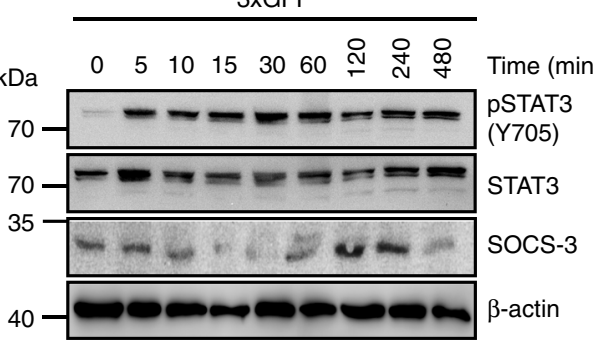

HIL-23

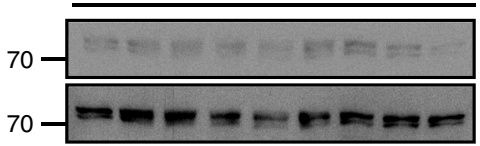

PSTAT3 (Y705)

STAT3

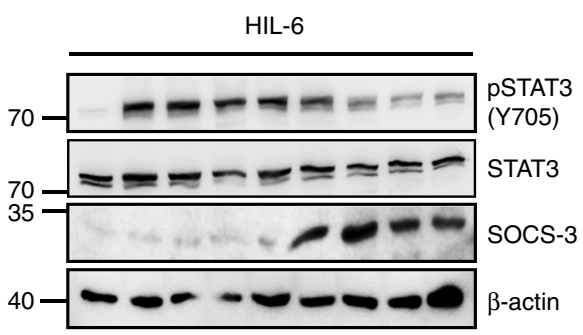

Fig. 5 SyCyRs for homodimeric IL-23R (SyCyR(IL-23R)) induced signal transduction. a Schematic illustration of homodimeric IL-23R SyCyR and GFP-GFP fusion protein. $G_{V H H^{-I L}-23 R: G_{V H H}}$ fused to 17 aa of the ECD, TMD, and ICD of IL-23R. b Proliferation of Ba/F3-SyCyR(IL-23R) cells with HIL-6 and GFP: mCherry fusion proteins cultured in the presence of the indicated synthetic ligands $(6.25 \mathrm{ng} / \mathrm{ml})$ or HIL-6 $(10 \mathrm{ng} / \mathrm{ml})$. Stimulation with mCherry was made with the same volume as with GFP (0.25\%). One representative experiment out of three is shown. Results are mean \pm s.d. of three replicates. $\mathbf{c}$ Proliferation of Ba/F3-SyCyR(IL-23R) with HIL-23, Ba/F3-IL-12Rß1-IL-23R, and Ba/F3-gp130 cells with 3xGFP and HIL-23 cultured in the presence of ligands (0.1 to $1600 \mathrm{ng} / \mathrm{ml}$ ). One representative experiment out of six is shown. Results are mean \pm s.d. of three replicates. d JAK activation in Ba/F3-SyCyR(IL-23R) cells. Cells were stimulated with conditioned supernatants containing $100 \mathrm{ng} / \mathrm{ml}$ of the indicated synthetic ligands or HIL-6 (100 ng/ml) for $20 \mathrm{~min}$. Equal amounts of total protein $(50 \mu \mathrm{g} / \mathrm{lane})$ were analyzed for phospho-JAK2 and JAK2. Western blot data show one representative experiment out of three. e STAT3, ERK1/2, and AKT activation in Ba/F3-SyCyR(IL-23R) cells stimulated with $100 \mathrm{ng} / \mathrm{ml}$ of the indicated ligands for 30 min. Stimulation with mCherry was made with the same volume as with GFP (2\%). Equal amounts of total protein ( $50 \mu \mathrm{g} /$ lane) were analyzed for phospho-STAT3/ERK1/2/AKT and STAT3/ERK1/2/AKT. Western blot data show one representative experiment out of three. $\mathbf{f B a} / \mathrm{F3}-\mathrm{SyCyR}$ (IL-23R) cells were stimulated with 3xGFP (100 $\mathrm{ng} / \mathrm{ml}), \mathrm{HIL}-23(25 \mathrm{ng} / \mathrm{ml})$, and HIL-6 $(25 \mathrm{ng} / \mathrm{ml})$ for 0-480 min. Equal amounts of total protein (50 $\mu \mathrm{g} / \mathrm{lane})$ were analyzed for phospho-STAT3, STAT3, SOCS3, and $\beta$-actin. Western blot data show one representative experiment out of three

Germany). Murine Ba/F3-gp130 cells transduced with human gp130 were provided by Immunex (Seattle, WA, USA) ${ }^{42}$. The packaging cell line Phoenix-Eco was obtained from Ursula Klingmüller (DKFZ, Heidelberg, Germany) ${ }^{43}$. Ba/F3-gp130 cells with murine IL-12R $\beta 1$ and murine IL-23R have been described previously ${ }^{18}$. All cell lines were grown in Dulbecco's modified Eagle medium (DMEM) highglucose culture medium (GIBCO ${ }^{\circledR}$, Life Technologies, Darmstadt, Germany) supplemented with $10 \%$ fetal calf serum $\left(\mathrm{GIBCO}^{\oplus}\right.$, Life Technologies, Darmstadt, Germany), $60 \mathrm{mg} / \mathrm{l}$ penicillin and $100 \mathrm{mg} / \mathrm{l}$ streptomycin (Genaxxon Bioscience $\mathrm{GmbH}$, Ulm, Germany) at $37^{\circ} \mathrm{C}$ with $5 \% \mathrm{CO}_{2}$ in a water saturated atmosphere. $\mathrm{Ba} /$ F3-gp130 cells were maintained in the presence of Hyper-IL-6 (HIL-6), a fusion protein of IL- 6 and the soluble IL-6R, which mimics IL- 6 trans-signaling ${ }^{44}$. Either recombinant protein $(10 \mathrm{ng} / \mathrm{ml})$ or $0.2 \%(10 \mathrm{ng} / \mathrm{ml})$ of conditioned cell culture medium from a stable CHO-K1 clone secreting Hyper-IL-6 (stock solution approx. $5 \mu \mathrm{g} / \mathrm{ml}$ as determined by ELISA) were used to supplement the growth medium. $\mathrm{Ba} / \mathrm{F} 3-\mathrm{IL}-12 \mathrm{R} \beta 1$-IL-23R cells expressing murine IL-23R and murine IL-12R $\beta 1$ were stimulated with $0.2 \%(10 \mathrm{ng} / \mathrm{ml})$ of conditioned cell culture medium from a stable CHO-K1 clone secreting murine Hyper-IL-23 (HIL-23) in a concentration of approx. $5 \mu \mathrm{g} / \mathrm{ml}$, as determined by ELISA ${ }^{18}$. Phospho-STAT3 (Tyr705) (D3A7) (1:1000, cat. \#9145), STAT3 (124H6) (1:1000, cat. \#9139), phospho-p44/42 MAPK (ERK1/2) (Thr-202/Tyr-204) (D13.14.4E) (1:1000, cat. \#4370), p44/42 MAPK 
a

SyCyR(IL-23/2A) w/ vs. w/o GFP-mCherry (synthetic system)

SyCyR(IL-23R) w/ vs. w/o 3xGFP (synthetic system)

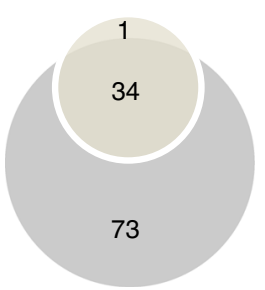

C
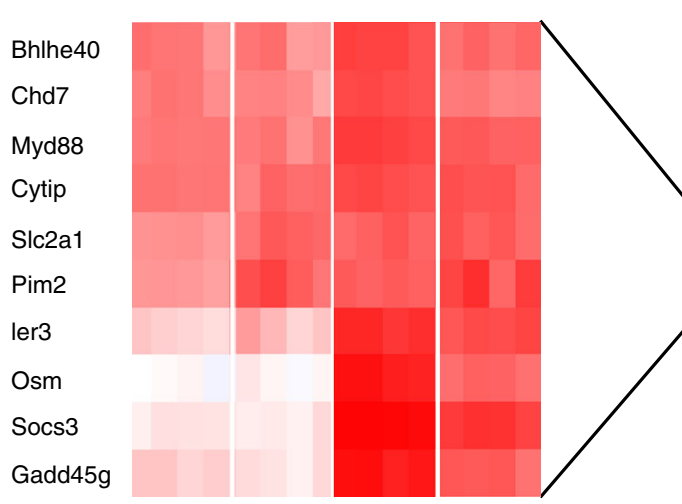

b

GFP-mCher

$\operatorname{SyCyR}(\mathrm{LL}-23 / 2 \mathrm{~A})$

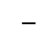

$-$

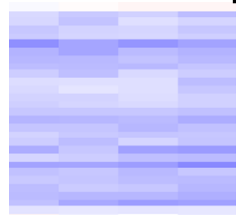

SyCyR(L-23R)
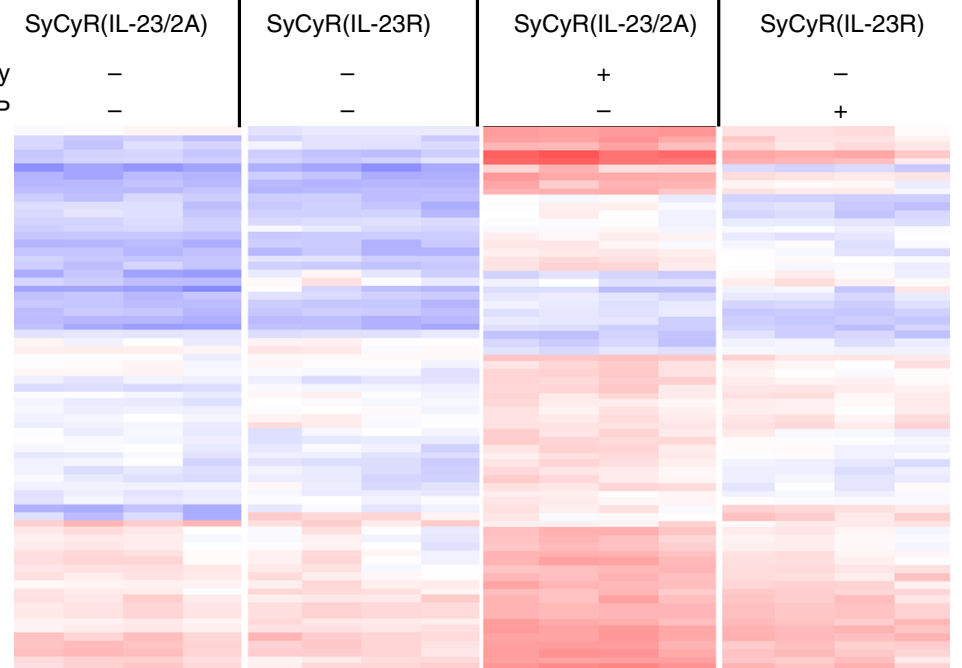

$x^{2}$
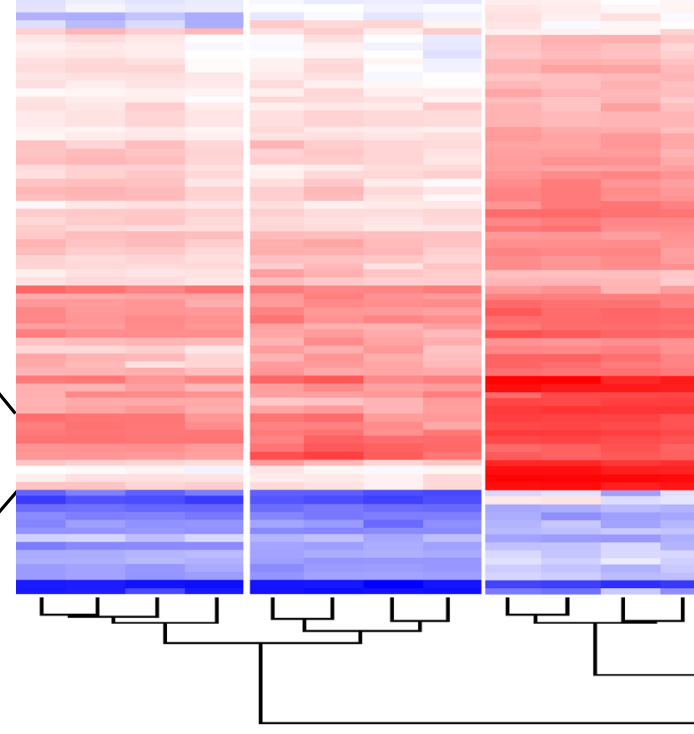

4.17

12.90

d

Top canonical pathways of SyCyR(IL-23R)

\begin{tabular}{|l|c|c|}
\hline \multicolumn{1}{|c|}{ Name } & $P$-value & Overlap \\
\hline IL-10 signaling & $6.40 \mathrm{E}-08$ & $\begin{array}{c}7.4 \% \\
5 / 68\end{array}$ \\
\hline $\begin{array}{l}\text { Th1 and Th2 activation } \\
\text { pathway }\end{array}$ & $3.66 \mathrm{E}-07$ & $3.2 \%$ \\
\hline Th1 pathway & & $6 / 185$ \\
\hline $\begin{array}{l}\text { Role of macrophages, } \\
\text { fibroblasts and } \\
\text { endothelial cells in } \\
\text { rheumatoid arthritis }\end{array}$ & $1.98 \mathrm{E}-06$ & $3.7 \%$ \\
\hline
\end{tabular}

Fig. 6 Microarray analysis of Ba/F3-SyCyR(IL-23R) cells. a Venn-diagram of at least 1.5-fold ( $p$-value $\leq 0.01$ ) up- or downregulated mRNAs of Ba/F3SyCyR(IL-23R) cells stimulated with $100 \mathrm{ng} / \mathrm{ml} 3 x$ GFP (yellow) and Ba/F3-SyCyR(IL-23/2A) cells stimulated with $100 \mathrm{ng} / \mathrm{ml} \mathrm{GFP-mCherry} \mathrm{(light} \mathrm{gray)} \mathrm{for}$ $60 \mathrm{~min}$. Microarray analysis was performed using samples of four independent biological replicates. $\mathbf{b}$ Heat map comparing mRNA levels of Ba/F3-SyCyR (IL-23R) and Ba/F3-SyCyR(IL-23/2A) stimulated and unstimulated as described in a. c Higher magnification of selected mRNAs from b. d Ingenuity pathway analysis (IPA) revealed the top five canonical pathways of Ba/F3-SyCyR(IL-23/2A) vs. Ba/F3-SyCyR(IL-23R) 
(ERK1/2) (1:1000, cat. \#9102), phospho-AKT (Ser473) (D9E) (1:000, cat. \#4060), AKT (1:1000, cat. \#9272S), phospho-JAK1 (Tyr1022/1023) (1:000, cat. \#3331), JAK1 (6G4) (1:1000, cat. \#3344S), phospho-JAK2 (Tyr1007/1008) (1:1000, cat. \#3771), JAK2 (D2E12) (1:000, cat. \#3230), phospho-TYK2 (Tyr1054/1055) (1:000, cat. \#9321), TYK2 (1:000, cat. \#9312), GFP (4B10) (1:000, cat. \#2955) and myc (71D10), (1:1000 for western blotting and $1.2 \mu \mathrm{g}$ for flow cytometry, cat. \#2278) monoclonal antibodies (mAbs) were obtained from Cell Signaling Technology (Frankfurt, Germany). mCherry (1:1000, cat. 31451) was obtained from Thermo Fisher Scientific (Waltham, MA, USA). Flag (DYKDDDDK) (1:1000 for western blotting and 1:100 for flow cytometry, cat. F7425) and $\gamma$-tubulin (1:5000, cat. T5326) mAbs were obtained from Sigma Aldrich (Munich, Germany). Human CIS3/SOCS3 (C204) mAb (1:500, cat. JP18391) was obtained from ImmunoBiological Laboratories Co, Ltd. (Fujioka, Japan). $\beta$-actin (C4) mAb (1:500, cat. sc47778) was obtained from Santa Cruz Biotechnology (Dallas, USA). Peroxidaseconjugated secondary mAbs (1:2500, cat. 31462, cat. 31451) were obtained from Pierce (Thermo Fisher Scientific, Waltham, MA, USA). Alexa Fluor 488 conjugated Fab goat anti-rabbit IgG (1:100, cat. A11070) was obtained from Thermo Fisher Scientific (Waltham, MA, USA). PageRuler Prestained Protein Ladder (cat. \#26616) was obtained from Thermo Fisher Scientific (Waltham, MA, USA).
Construction SyCyRs and synthetic ligands. pcDNA3.1- $\mathrm{G}_{\mathrm{VHH}}-\mathrm{IL}-23 \mathrm{R}$ expression vector was generated by fusion of coding sequences for human IL-11R signal peptide (Q14626, aa 1-24) followed by sequences for myc tag (EQKLISEEDL), GFP-nanobody $\left(\mathrm{G}_{\mathrm{VHH}}\right)^{15}$ and murine IL-23R (Q8K4B4) comprising amino acids A358 to K644 representing 17 aa of the extracellular domain, the transmembrane domain and the cytoplasmic part of the receptor. The cDNA coding for $\mathrm{G}_{\mathrm{VHH}}-\mathrm{IL}-$ $12 \mathrm{R} \beta 1$ was generated by insertion of cDNA coding for murine IL-12R $\beta 1$ (Q60837, aa A551-A738, representing 15 aa of the extracellular domain, the transmembrane domain and the cytoplasmic part of the receptor), which was amplified by PCR from $\mathrm{p} 409-\mathrm{IL}-12 \mathrm{R} \beta 1^{18}$, into expression vector pcDNA3.1-G $\mathrm{VHH}_{\mathrm{VH}}$-IL-23R, where the coding sequence for IL-23R was removed. pcDNA3.1- $\mathrm{C}_{\mathrm{VHH}}-\mathrm{IL}-23 \mathrm{R}$ expression vector was generated by fusion of coding sequences for human IL-11R signal peptide (Q14626, aa 1-24) followed by sequences for Flag-tag (DYKDDDDK), mCherry-nanobody $\left(\mathrm{C}_{\mathrm{VHH}}\right)^{14}$ and murine IL-23R (Q8K4B4) comprising amino acids A358 to K644 (representing 17 aa of the extracellular domain, the transmembrane domain and the cytoplasmic part of the receptor). To combine cDNAs coding for $\mathrm{C}_{\mathrm{VHH}} \mathrm{IL}-23 \mathrm{R}$ and $\mathrm{G}_{\mathrm{VHH}}-\mathrm{IL}-12 \mathrm{R} \beta 1$ in one open reading frame, cDNAs coding for both SyCyRs were amplified by PCR and cloned into pMK-FUSIO coding for the self-processing $2 \mathrm{~A}$-peptide ${ }^{4,45}$. The cDNA coding for IL-23R- a

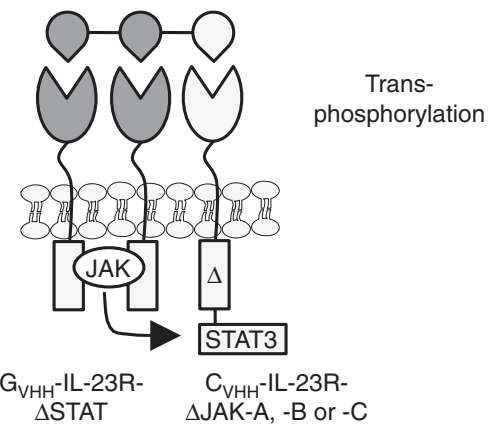

b

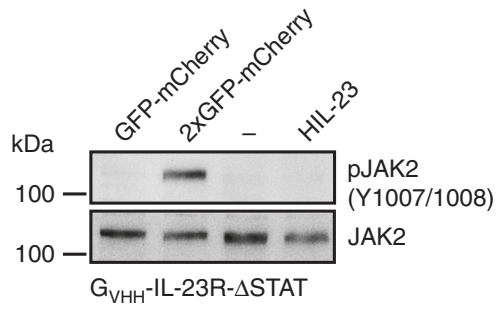

C

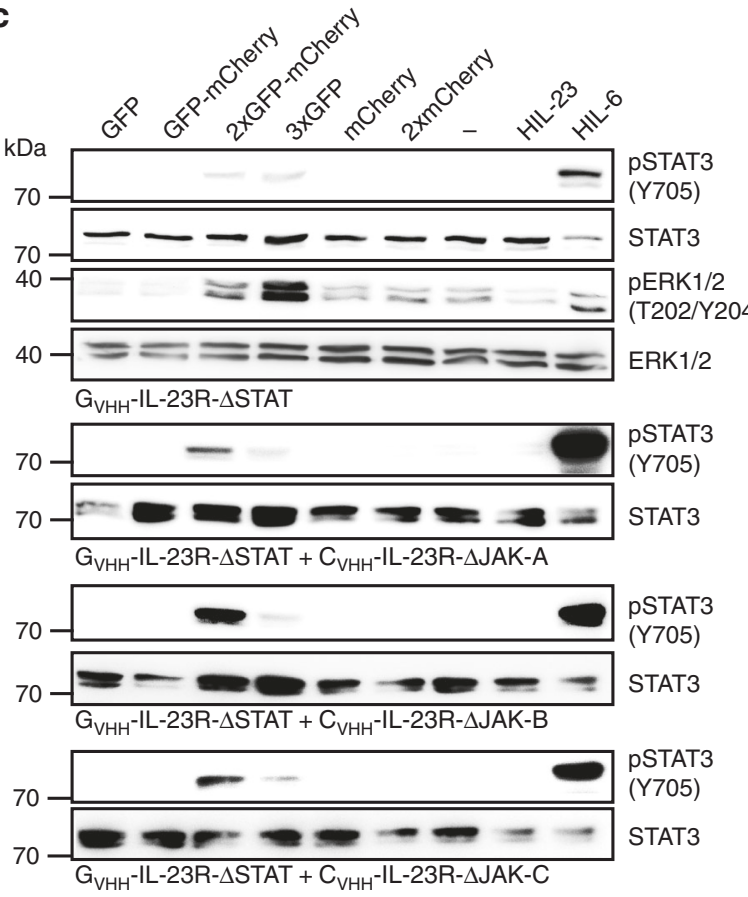

d

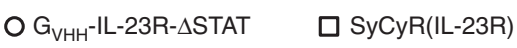

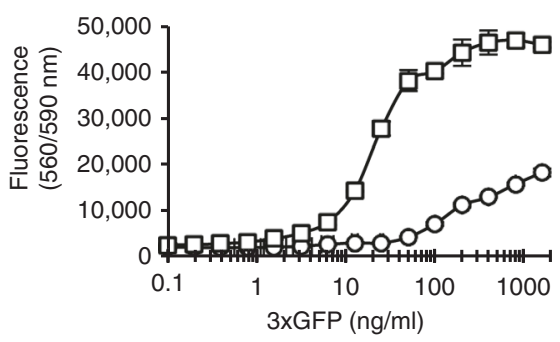

e
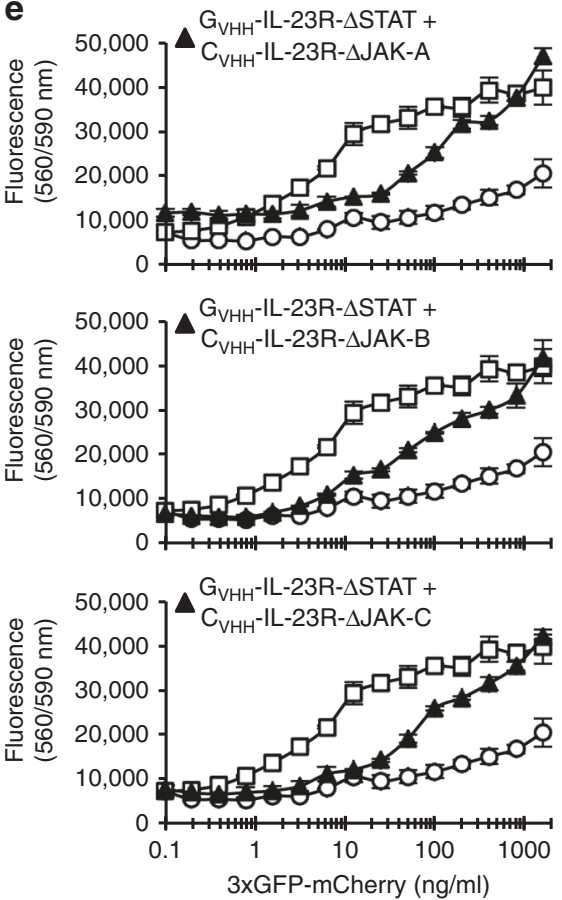
$\Delta$ STAT $(\Delta 503)$ was amplified by PCR from pcDNA3.1-IL-23R- $\Delta$ STAT $(\Delta 503)^{18}$ and inserted into pcDNA3.1- $\mathrm{G}_{\mathrm{VHH}}-\mathrm{IL}-23 \mathrm{R}$, where the sequence for IL-23R was removed. Accordingly, cDNAs coding for $\Delta$ JAK-A (IL-23R- $\Delta 403-417$ ), $\Delta$ JAK-B (IL-23R- $\Delta 455-479$ ), and $\Delta$ JAK-C (IL-23R- $\Delta 403-479)$ were amplified by PCR from p409-IL-23R- $\Delta 403-417$, -IL-23R- $\Delta 455-479$, and -IL-23R- $\Delta 403-479^{20}$ containing 16 aa of the extracellular domain, the transmembrane domain and the shortened cytoplasmic part of the receptor and inserted into pcDNA3.1- $\mathrm{C}_{\mathrm{VHH}}-\mathrm{IL}-23 \mathrm{R}$, where the coding sequence for IL-23R was removed. p409-gp130 (chemically synthesized by GeneArt, Thermo Fisher Scientific, Waltham, MA, USA) was digested by EcoRI, NotI and ligated in pcDNA3.1-G $\mathrm{G}_{\mathrm{VH}}-\mathrm{IL}-23 \mathrm{R}$, which was digested by the same enzymes to generate pcDNA3.1- $\mathrm{G}_{\mathrm{VHH}}$-gp130 containing 16 aa of the extracellular domain, the transmembrane domain and the intracellular domain of the human receptor. cDNA coding for gp130- $\triangle$ STAT was amplified by PCR (aa 1-758) and ligated to the same vector mentioned before. The expression cassette for 3xGFP was obtained from pmEGFP-13 (Addgene, Cambridge, MA, USA) ${ }^{46}$ and inserted into pcDNA3.1 expression vector containing the IL-11R signal peptide and an $\mathrm{N}$ terminal Flag-tag (DYKDDDDK). To generate pcDNA3.1-2xGFP-mCherry, one GFP from pcDNA3.1-3xGFP was removed and replaced with mCherry from pcDNA3.1-mCherry. To create single GFP, the cDNA coding for GFP was amplified by PCR from pcDNA3.1-2xGFP-mCherry and inserted into the pcDNA3.1 expression vector. To create pcDNA3.1-GFP-mCherry, cDNA coding for mCherry was inserted into pcDNA3.1-GFP. For retroviral transduction of Ba/ F3-gp130 cells two retroviral plasmids with different resistance genes, pMOWSpuro $^{43}$ coding for puromycin resistance and pMOWS-hygro ${ }^{4}$ for hygromycin B resistance, have been used. Expression cassettes coding for $\mathrm{G}_{\mathrm{VHH}}-\mathrm{IL}-23 \mathrm{R}, \mathrm{C}_{\mathrm{VHH}^{-}}$ IL-23R-2A-G $\mathrm{VHH}-\mathrm{IL}-12 \mathrm{R} \beta 1(\mathrm{SyCyR}(\mathrm{IL}-23 / 2 \mathrm{~A})), \mathrm{C}_{\mathrm{VHH}}-\mathrm{IL}-23 \mathrm{R}, \mathrm{C}_{\mathrm{VHH}}-\mathrm{IL}-23 \mathrm{R}-$ $\Delta$ JAK-A ( $\Delta 403-417), C_{\mathrm{VHH}}-\mathrm{IL}-23 \mathrm{R}-\Delta \mathrm{JAK}-\mathrm{B}(\Delta 455-479), \mathrm{C}_{\mathrm{VHH}}-\mathrm{IL}-23 \mathrm{R}-\Delta \mathrm{JAK}-\mathrm{C}$ ( $\triangle 403-479)$, and $\mathrm{G}_{\mathrm{VHH}^{-}}$gp130 were inserted into pMOWS-puro, whereas those for $\mathrm{G}_{\mathrm{VHH}}$-IL-12R $\beta 1, \mathrm{G}_{\mathrm{VHH}}-\mathrm{IL}-23 \mathrm{R}-\Delta \mathrm{STAT}(\Delta 503)$ and $\mathrm{G}_{\mathrm{VH}}-\mathrm{gp} 130-\Delta \mathrm{STAT}$ were inserted into pMOWS-hygro. All generated expression plasmids have been verified by sequencing.

Transfection and selection of cells. Transfection of U4C and CHO-K1 cells with indicated plasmids was performed using TurboFect ${ }^{\text {tw }}$ (Thermo Fisher Scientific, Waltham, MA, USA). Ba/F3-gp130 cells were retrovirally transduced with the pMOWS expression plasmids coding for the various synthetic receptor variants ${ }^{18}$. Transduced cells were grown in standard DMEM medium as described above

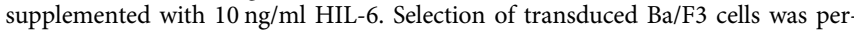
formed with puromycin $(1.5 \mu \mathrm{g} / \mathrm{ml})$ or hygromycin B $(1 \mathrm{mg} / \mathrm{ml})$ (Carl Roth, Karlsruhe, Germany) or both for at least 2 weeks. Afterwards, HIL- 6 was washed away and the generated Ba/F3-gp130 cell lines were selected for GFP:mCherrydependent growth and analyzed for receptor cell surface expression. Stable transfected CHO-K1 cells secreting GFP:mCherry proteins were selected with $1.125 \mathrm{mg} /$ ml G-418 sulfate (Genaxxon, Biosciences, Ulm, Germany). High-expressing cell clones were identified by western blotting.

Expression and purification of $\mathbf{G}_{\mathrm{VHH}}-\mathbf{C}_{\mathrm{VHH}}$ from E.coli. The cDNA coding for the bispecific antibody $\mathrm{G}_{\mathrm{VHH}}{ }^{-} \mathrm{C}_{\mathrm{VHH}}$ was generated and subcloned in pet23a. The resulting bispecific antibody sequence was flanked by an $\mathrm{N}$-terminal PelB leader sequence for periplasmic expression and a 3 ' hexahistidine sequence for purification. Proteins were expressed in the E.coli strain BL21-Rosetta. Bacteria were incubated in $21 \mathrm{LB}$-media containing ampicillin 1:1000 $(100 \mu \mathrm{g} / \mathrm{ml})$ and chloramphenicol 1:1000 $(34 \mu \mathrm{g} / \mathrm{ml})$ at $37^{\circ} \mathrm{C}$, until optical density reached $0.6-0.9$. Then $1 \mathrm{mM}$ IPTG was added. Bacteria were harvested by centrifugation $(5000 \times g, 30$ min, $4{ }^{\circ} \mathrm{C}$ ) $4 \mathrm{~h}$ after IPTG induction. A cOmplete protease inhibitor tablet (Roche, Mannheim, Germany) was added and supernatant was filtered through a $0.45 \mu \mathrm{m}$ bottle top filter. Proteins were purified via IMAC chromatography and eluted with $500 \mathrm{mM}$ imidazole.

Cell viability assay. To remove the cytokines, $\mathrm{Ba} / \mathrm{F} 3$-gp130 cell lines were washed three times with sterile PBS. In all, $5 \times 10^{3}$ cells were suspended in DMEM supplemented with $10 \%$ FCS, $60 \mathrm{mg} / \mathrm{l}$ penicillin and $100 \mathrm{mg} / \mathrm{l}$ streptomycin and cultured for 3 days in a final volume of $100 \mu \mathrm{l}$ with or without cytokines/fluorescent proteins as indicated. The CellTiter-Blue Cell Viability Assay (Promega, Karlsruhe, Germany) was used to estimate the number of viable cells by recording the fluorescence (excitation $560 \mathrm{~nm}$, emission $590 \mathrm{~nm}$ ) using the Infinite M200 PRO plate reader (Tecan, Crailsheim, Germany) immediately after adding $20 \mu \mathrm{l}$ of reagent per well (time point 0 ) and up to $2 \mathrm{~h}$ after incubation under standard cell culture conditions. All of the values were measured in triplicate per experiment. Fluorescence values were normalized by subtraction of time point 0 values.

Stimulation assays. For analysis of STAT3, ERK1/2 and AKT, JAK1, JAK2, and TYK2 activation $\mathrm{Ba} / \mathrm{F} 3$-gp130 cell lines expressing various SyCyR variants were washed three times with sterile PBS and incubated in serum-free DMEM for at least $2 \mathrm{~h}$. Cells were stimulated with conditioned supernatants of GFP:mCherry fusion proteins as indicated, harvested, frozen in liquid nitrogen, and lysed. Protein concentration of cell lysates was determined by BCA Protein Assay (Pierce, Thermo Fisher Scientific,Waltham, MA, USA). Analysis of STAT3, ERK1/2, AKT, JAK1, JAK2, and TYK2 activation, SOCS3 and $\beta$-actin expression was done by immunoblotting using $25-75 \mu \mathrm{g}$ proteins from total cell lysates and detection with phospho-STAT3 (Tyr705) (D3A7) (1:1000, cat. \#9145), phospho-ERK1/2 (Thr202/Tyr-204) (D13.14.4E) (1:1000, cat. \#4370), phospho-AKT (Ser473) (D9E) (1:000, cat. \#4060), phospho-JAK1 (Tyr1022/1023) (1:000, cat. \#3331), phosphoJAK2 (Tyr1007/1008) (1:1000, cat. \#3771), phospho-TYK2 (Tyr1054/1055) (1:000, cat. \#9321), SOCS3 (C204) (1:500, cat. JP18391) and $\beta$-actin (C4) (1:500, cat. sc47778) mAbs.

Western blotting. Defined amounts of proteins from cell lysates were loaded per lane, separated by sodium dodecyl sulfate polyacrylamide gel electrophoresis under reducing conditions and transferred to polyvinylidene fluoride (PVDF) membranes (Carl Roth, Karlsruhe, Germany). The membranes were blocked in $5 \%$ fat-free dried skimmed milk (Carl Roth, Karlsruhe, Germany) in TBS-T (10 mM Tris-HCl (Carl Roth, Karlsruhe, Germany) pH 7.6, $150 \mathrm{mM} \mathrm{NaCl}$ (AppliChem, Darmstadt, Germany), 1\% Tween 20 (Sigma Aldrich, Munich, Germany)) and probed with the indicated primary antibodies in 5\% fat-free dried skimmed milk in TBS-T (STAT3 (124H6) (1:1000, cat. \#9139), $\gamma$-tubulin (1:5000, cat. T5326), GFP (4B10) (1:000, cat. \#2955) mAbs) or 5\% BSA (Carl Roth, Karlsruhe, Germany) in TBS-T (phospho-STAT3 (Tyr705) (D3A7) (1:1000, cat. \#9145), phospho-ERK1/2 (Thr-202/ Tyr-204) (D13.14.4E) (1:1000, cat. \#4370), ERK1/2 (1:1000, cat. \#9102), phosphoAKT (Ser473) (D9E) (1:000, cat. \#4060), AKT (1:1000, cat. \#9272S), myc (71D10), (1:1000, cat. \#2278) and Flag (DYKDDDDK) (1:1000, cat. F7425), SOCS3 (C204) (1:500, cat. JP18391), phospho-JAK1 (Tyr1022/1023) (1:000, cat. \#3331), JAK1 (6G4) (1:1000, cat. \#3344S), phospho-JAK2 (Tyr1007/1008) (1:1000, cat. \#3771), JAK2 (D2E12) (1:000, cat. \#3230), phospho-TYK2 (Tyr1054/1055) (1:000, cat. \#9321), TYK2 (1:000, cat. \#9312) and $\beta$-actin (C4) (1:500, cat. sc-47778) mAbs) at $4^{\circ} \mathrm{C}$ overnight. After washing, the membranes were incubated with secondary peroxidase-conjugated antibodies (Thermo Fisher Scientific, Waltham, MA, USA, cat. 31462, cat. 31451) 1:2500 diluted in 5\% fat-free dried skimmed milk in TBS-T for $1 \mathrm{~h}$ at room temperature. PageRuler Prestained Protein Ladder (Thermo Fisher Scientific, Waltham, MA, USA, cat. \#26616) was used as MW Marker. The Immobilon $^{\text {mt }}$ Western Chemiluminescent HRP Substrate (Merck Chemicals GmbH, Darmstadt, Germany) and the ChemoCam Imager (INTAS Science

Fig. 7 Engineered heterotrimeric SyCyRs of IL-23R are capable of STAT3 trans-phosphorylation in transduced Ba/F3-gp130 cells. a Schematic illustration of

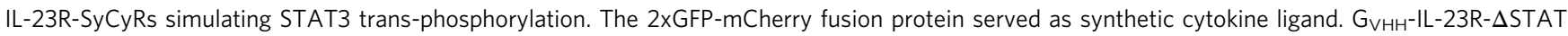
consists of the GFP-nanobody fused to 16 aa of the extracellular part, the transmembrane and intracellular domains of the IL-23R lacking STAT-binding motifs. The $\mathrm{C}_{\mathrm{VHH}}-\mathrm{IL}-23 \mathrm{R}-\Delta \mathrm{JAK}$ variants consist of the mCherry-nanobody fused to 16 aa of the extracellular part, the transmembrane and intracellular domains of the IL-23R lacking the JAK activation site ( $\Delta$ JAK-A,-B,-C). b Analysis of JAK activation in Ba/F3-IL-23R- $\Delta$ STAT cells. Cells were washed three times, starved, and stimulated with $100 \mathrm{ng} / \mathrm{ml}$ of the indicated synthetic ligands for 20 min. Cellular lysates were prepared, and equal amounts of total protein $(50 \mu \mathrm{g} /$ lane) were loaded on SDS gels, followed by immunoblotting using specific antibodies for phospho-JAK2 and JAK2. Western blot data show

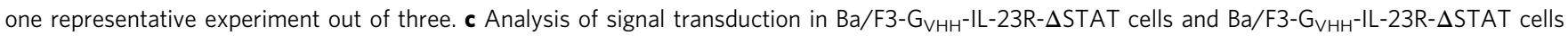

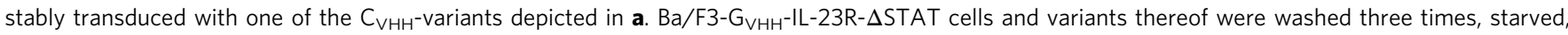
stimulated with $4 \% \mathrm{CHO}-\mathrm{K} 1$ conditioned supernatant containing mCherry, $2 x \mathrm{mCherry}$ or conditioned supernatant containing $100 \mathrm{ng} / \mathrm{ml}$ of the other indicated synthetic ligands for $60 \mathrm{~min}$. Stimulation with HIL-23 $(10 \mathrm{ng} / \mathrm{ml})$ for $60 \mathrm{~min}$ and HIL-6 $(10 \mathrm{ng} / \mathrm{ml})$ for 15 min was used as control. Cellular lysates were prepared, and equal amounts of total protein (for STAT3 analysis $25 \mu \mathrm{g} /$ lane for HIL-6 and $50 \mu \mathrm{g} /$ lane for other ligands, for ERK1/2 analysis $12.5 \mu \mathrm{g} /$ lane for HIL-6 and $75 \mu \mathrm{g}$ /lane for other ligands) were loaded on SDS gels, followed by immunoblotting using specific antibodies for phospho-STAT3/ERK1/ 2 and STAT3/ERK1/2. Western blot data show one representative experiment out of two. d, e Cellular proliferation of Ba/F3-SyCyR(IL-23R), Ba/F3-G IL-23RASTAT cells and variants thereof with 3 XGFP or 2xGFP-mCherry fusion proteins. Equal numbers of cells were cultured for 3 days in the presence of the indicated ligands $(0.1-1600 \mathrm{ng} / \mathrm{ml})$. Proliferation was measured using the colorimetric CellTiter-Blue cell viability assay. One representative experiment out of four is shown. Results are mean \pm s.d. of three replicates 
a

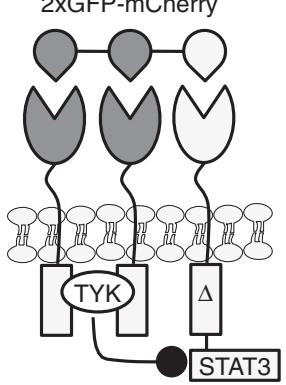

$\mathrm{G}_{\mathrm{VHH}}-\mathrm{IL}-12 \mathrm{R} \beta 1 \quad \mathrm{C}_{\mathrm{VH}-\mathrm{IL}-23 \mathrm{R}-}$

No trans-

phosphorylation b

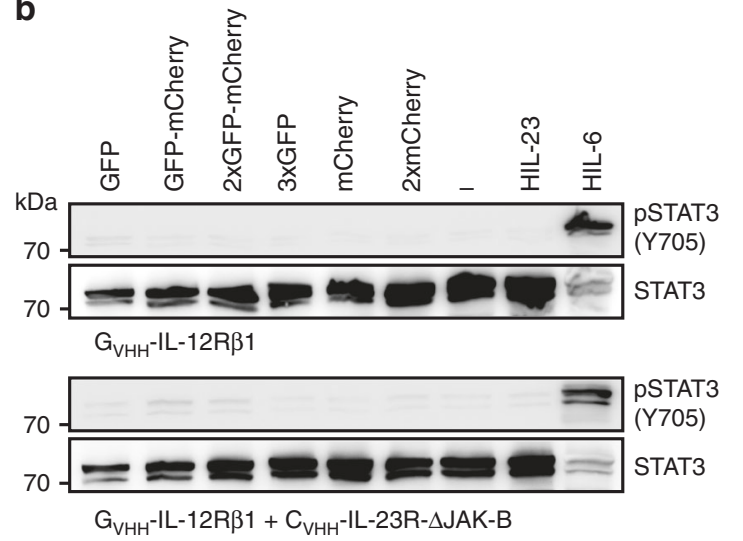

C

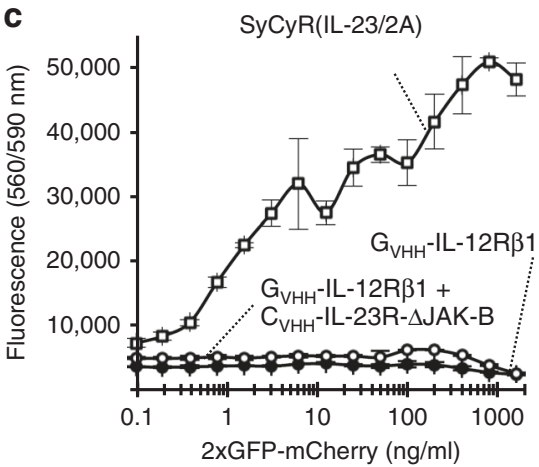

d

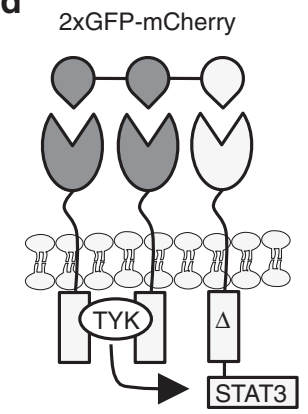

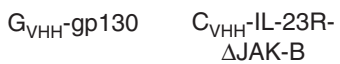

Trans-

phosphorylation

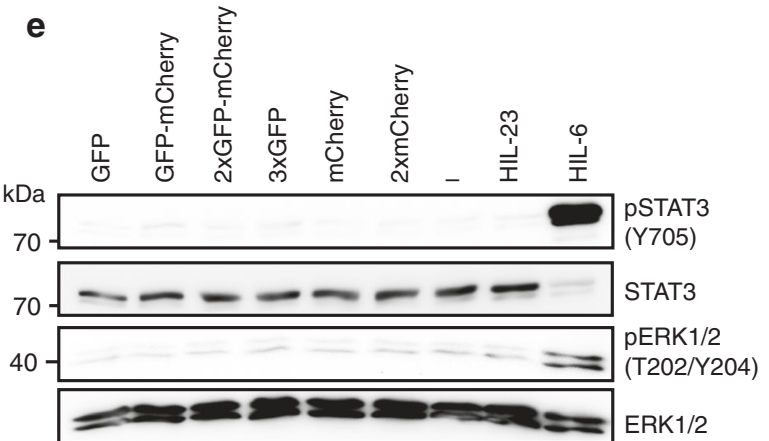

$\mathrm{G}_{\mathrm{VHH}}-\mathrm{gp} 130-\Delta \mathrm{STAT}$

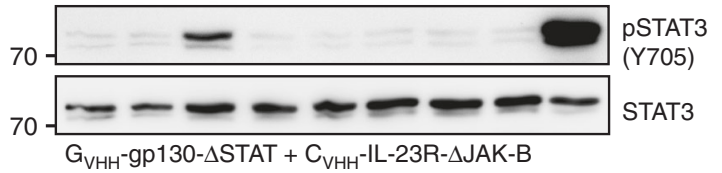

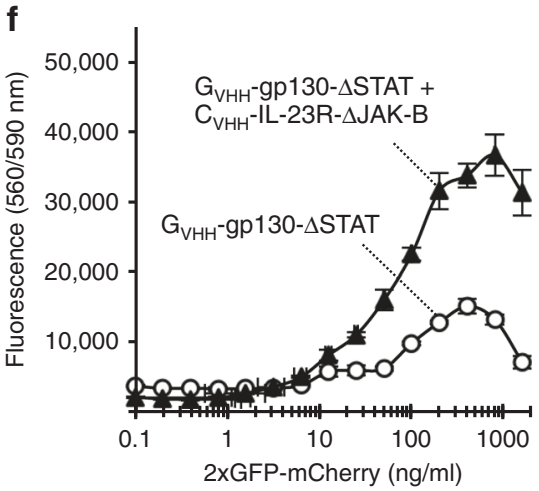

Fig. 8 Engineered heterotrimeric SyCyRs based on $G_{V H}-I L-12 R \beta 1$ and $G_{V H}-g p 130$ homodimerization fail in STAT3 trans-phosphorylation. a Schematic illustration of IL-12R R1-SyCyRs simulating STAT3 trans-phosphorylation using 2xGFP-mCherry. GVHH-IL-12Rß1: GFP-nanobody fused to 15 aa of ECD, TMD, and ICD of IL-12R $\beta 1$, lacking any STAT-binding motifs. $\mathrm{C}_{\mathrm{VHH}}-\mathrm{IL}-23 \mathrm{R}-\Delta \mathrm{JAK}-\mathrm{B}$ variant: mCherry-nanobody fused to 16 aa of ECD, the TMD and ICD of the IL23R lacking JAK activation site ( $\triangle \mathrm{JAK}-\mathrm{B})$. b STAT3 activation in indicated Ba/F3-GVH-IL-12R 31 cells lines were stimulated with $16 \%$ CHO-K1 conditioned supernatant containing mCherry, 2xmCherry or conditioned supernatant containing $400 \mathrm{ng} / \mathrm{ml}$ of the other indicated ligands for 60 min or with HIL-23 $(10 \mathrm{ng} / \mathrm{ml})$ for $60 \mathrm{~min}$ and HIL-6 $(10 \mathrm{ng} / \mathrm{ml})$ for $15 \mathrm{~min}$. Total proteins $(25 \mu \mathrm{g} /$ lane for HIL-6 and $50 \mu \mathrm{g} /$ lane for other ligands) were analyzed for phosphoSTAT3 and STAT3. Western blot data show one representative experiment out of three. c Proliferation of indicated Ba/F3-SyCyR(IL-23/2A) and Ba/F3-

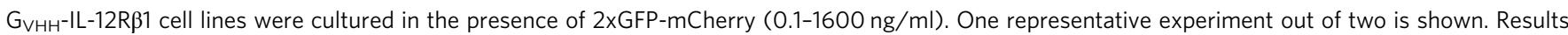
are mean \pm s.d. of three replicates. d Schematic illustration of gp130-SyCyRs simulating STAT3 trans-phosphorylation with 2xGFP-mCherry. GVH-gp130$\triangle$ STAT: GFP-nanobody fused to 13 aa of the ECD, the TMD and ICD of gp130 lacking the STAT-binding motifs. $C_{V H H^{-}}$IL-23R- $\Delta$ JAK-B: mCherry-nanobody fused to 16 aa of the ECD, the TMD and ICD of the IL-23R lacking JAK activation site. e STAT3 and ERK1/2 activation in indicated Ba/F3-G ${ }_{V H H}{ }^{-g p 130-}$ $\triangle$ STAT cell lines were stimulated with $8 \% \mathrm{CHO}-\mathrm{K} 1$ conditioned supernatant containing mCherry, $2 x m$ Cherry or conditioned supernatant containing 200 $\mathrm{ng} / \mathrm{ml}$ of the other indicated ligands for $60 \mathrm{~min}$ or HIL-23 $(10 \mathrm{ng} / \mathrm{ml})$ for $60 \mathrm{~min}$ or HIL-6 $(10 \mathrm{ng} / \mathrm{ml})$ for $15 \mathrm{~min}$. Equal amounts of total protein (for STAT3 analysis $25 \mu \mathrm{g} /$ lane for HIL-6 and $50 \mu \mathrm{g} /$ lane for other ligands. For ERK1/2 analysis $12.5 \mu \mathrm{g} /$ lane for HIL- 6 and $75 \mu \mathrm{g} /$ lane for other ligands) were analyzed for phospho-STAT3/ERK1/2 and STAT3/ERK1/2. Western blot data show one representative experiment out of two. $\mathbf{f}$ Proliferation of indicated Ba/F3$\mathrm{G}_{\mathrm{VH}}{ }^{-\mathrm{gp}} 130-\Delta \mathrm{STAT}$ cells lines were cultured in the presence of $2 x \mathrm{GFP}-\mathrm{mCherry}(0.1-1600 \mathrm{ng} / \mathrm{ml})$. One representative experiment out of four is shown. Results are mean \pm s.d. of three replicates

Imaging Instruments $\mathrm{GmbH}$, Göttingen, Germany) were used for signal detection. For re-probing with another primary antibody, the membranes were stripped in $62.5 \mathrm{mM}$ Tris- $\mathrm{HCl}$ (Carl Roth, Karlsruhe, Germany) pH 6.8, 2\% SDS (Carl Roth, Karlsruhe, Germany) and 0.1\% $\beta$-mercaptoethanol (Sigma Aldrich, Munich, Germany) for $30 \mathrm{~min}$ at $60^{\circ} \mathrm{C}$ and blocked again.

The band intensities of the western blots (Fig. 4f) were quantified using ImageJ software. Uncropped images of western blots are presented in Supplementary Fig. 13.

Cell surface detection of cytokine receptors. To detect cell surface expression of the synthetic cytokine receptors, stably transduced Ba/F3-gp130 cells were washed with FACS buffer (PBS containing $1 \%$ BSA) and incubated at $5 \times 10^{5}$ cells $/ 100 \mu \mathrm{l}$ FACS buffer supplemented with a 1:100 dilution of anti-myc (71D10), (cat. \#2278) or $1.2 \mu \mathrm{g}$ anti-Flag (DYKDDDDK) (cat. F7425) mAbs for $1 \mathrm{~h}$ on ice. After a single wash with FACS buffer, cells were incubated in $100 \mu \mathrm{l}$ FACS buffer containing a 1:100 dilution of Alexa Fluor 488 conjugated Fab goat anti-rabbit IgG (cat. A11070) for $1 \mathrm{~h}$ on ice. Finally, cells were washed once with FACS buffer, suspended in 500 $\mu \mathrm{l}$ FACS buffer and analyzed by flow cytometry (BD FACSCanto II flow cytometer, BD Biosciences, San Jose, CA, USA). Data was evaluated using the FCS Express 4 Flow software (De Novo Software, Los Angeles, CA, USA).

Microarray analysis. Ba/F3-gp130 cells were grown in DMEM high-glucose culture medium supplemented with $10 \%$ fetal calf serum $\left(\mathrm{GIBCO}^{\oplus}\right.$, Life Technologies, Darmstadt, Germany), $60 \mathrm{mg} / \mathrm{l}$ penicillin and $100 \mathrm{mg} / \mathrm{l}$ streptomycin (Genaxxon Bioscience $\mathrm{GmbH}$, Ulm, Germany) at $37^{\circ} \mathrm{C}$ with $5 \% \mathrm{CO}_{2}$ in a water saturated atmosphere. In all, $10 \mathrm{ng} / \mathrm{ml}$ of conditioned cell culture medium from a stable CHO-K1 clone secreting Hyper-IL-6 (stock solution approx. $5 \mu \mathrm{g} / \mathrm{ml}$ as determined by ELISA) were used to supplement the growth medium. Ba/F3-gp130 cells were 
stable transduced with different receptor complexes (IL-12R $\beta 1-I L-23 R, \mathrm{C}_{\mathrm{VHH}}$-IL23R-2A-G $\mathrm{VHH}_{\mathrm{VH}}$-IL-12Rß1(SyCyR(IL-23/2A)) or G $\mathrm{VHH}_{\mathrm{VH}}-\mathrm{IL}-23 \mathrm{R}$ (SyCyR(IL-23R))), independently selected and cultivated for several weeks. Subsequently, Ba/F3-gp130 cell lines were washed four times with sterile PBS and incubated in serum-free DMEM for $3 \mathrm{~h}$. Equal numbers of cells $\left(2 \times 10^{6}\right)$ were stimulated with $100 \mathrm{ng} / \mathrm{ml}$ HIL-23, GFP-mCherry or $3 \times$ GFP for $1 \mathrm{~h}$ at $37^{\circ} \mathrm{C}$, independently. Stimulation with cell culture supernatant from untransfected $\mathrm{CHO}-\mathrm{K} 1$ cells was used as control. Total RNA extraction of four independent biological replicates was made with RNeasy Mini Kit (Qiagen, Hilden, Germany) according to the manufacturer's instructions. RNA quality was evaluated using an Agilent 2100 Bioanalyzer and only high-quality RNA (RIN $>8$ ) was used for microarray analysis. For this, total RNA (150 ng) was processed using the Ambion WT Expression Kit and the WT Terminal Labeling Kit (Thermo Fisher Scientific, Waltham, MA, USA) and hybridized on Affymetrix Mouse Gene ST 1.0 arrays containing about 28,000 probe sets. Staining and scanning were done according to the Affymetrix expression protocol. Expression console (Affymetrix, Freiburg, Germany) was used for quality control and to obtain annotated normalized RMA gene-level data (standard settings including sketch-quantile normalization). Statistical analyses were performed by utilizing the statistical programming environment $\mathrm{R}$ ( $\mathrm{R}$ Development Core Team $^{47}$ ) implemented in CARMAweb ${ }^{48}(1.5$-fold, $p$-value $\leq 0.01)$. Data were analyzed pairwise, $\mathrm{Ba} / \mathrm{F} 3-\mathrm{SyCyR}(\mathrm{IL}-23 / 2 \mathrm{~A})$ cells stimulated with vs. without 100 $\mathrm{ng} / \mathrm{ml}$ GFP-mCherry and Ba/F3-IL-12R $\beta 1$-IL-23R cells stimulated with vs. without $100 \mathrm{ng} / \mathrm{ml} \mathrm{HIL-23}$ and Ba/F3-SyCyR(IL-23R) cells stimulated with vs. without 100 $\mathrm{ng} / \mathrm{ml} 3 \mathrm{xGFP}$

GO term and pathway enrichment analyses ( $p<0.01$ of enrichment) of differential abundant transcripts $(1.5$-fold, $p$-value $\leq 0.01)$ were done with Ingenuity software (Qiagen, Hilden, Germany). Gene expression raw data are available at GEO (accession number GSE101569).

Animals. C57BL/6 mice (Janvier Labs) were obtained from the animal facility of the University of Düsseldorf. Mice were fed with a standard laboratory diet and given autoclaved tap water ad libitum. They were kept in an air-conditioned room with controlled temperature $\left(20-24^{\circ} \mathrm{C}\right)$, humidity $(45-65 \%)$, and day/night cycle (12 h light, $12 \mathrm{~h}$ dark). Mice were acclimatized for 1 week before entering the study. All procedures were performed in accordance with the national guidelines for animal care and were approved by the local Research Board for animal experimentation (LANUV, State Agency for Nature, Environment and Consumer Protection, approval number (Az. 84-02.04.2016.A025)).

Hydrodynamic-based in vivo gene delivery. Eight-week-old male C57BL/6 mice were transfected via tail vein injection of the plasmids pcDNA3.1- $\mathrm{G}_{\mathrm{VHH}}{ }^{-} \mathrm{gp} 130$ $(2.3 \mu \mathrm{g} / \mathrm{mouse})$ and/or pcDNA3.1-3xGFP $(1.28 \mu \mathrm{g} /$ mouse $)$ prepared in PBS as described previously ${ }^{49}$. Animals were allocated randomly to the various groups. The studies were sufficiently powered based on power calculation at $\alpha$ of 0.05 and $\beta$ of 0.2

Gene expression analysis of Saa1. RNA was isolated with TRIzol according to the manufacturer's instructions (Thermo Fisher Scientific, Waltham, MA, USA). Gene expression of Saa1 (QT00196623, Qiagen, Hilden, Germany) and Gapdh (forward: TGCACCACCAACTGCTTAG, reverse: GGATGCAGGGATGATGTTC) were performed using a One-step SYBR Kit. (Bio-Rad Laboratories, Hercules, CA, USA).

Preparation of liver lysates. Tissue protein extracts from liver were prepared on ice using the lysis buffer ( $50 \mathrm{mM}$ Tris-HCl (Carl Roth, Karlsruhe, Germany), 150 $\mathrm{mM} \mathrm{NaCl}$ (AppliChem, Darmstadt, Germany), 2 mM EDTA (Sigma Aldrich, Munich, Germany), $2 \mathrm{mM} \mathrm{NaF}$ (Sigma Aldrich, Munich, Germany), $1 \mathrm{mM}$ $\mathrm{Na}_{3} \mathrm{VO}_{4}$ (Sigma Aldrich, Munich, Germany), $1 \%$ Nonidet P40 BioChemica (AppliChem, Darmstadt, Germany) 1\% Triton X-100 (Sigma Aldrich, Munich, Germany) and cOmplete EDTA-free Protease inhibitor cocktail tablet (Roche Diagnostics, Mannheim, Germany) and analyzed by western blotting. Equal amounts of protein $(50 \mu \mathrm{g} / \mathrm{lane})$ were loaded. Western blotting was scored by an observer blinded to the groups.

Statistical analysis. Data are presented as mean \pm SEM. The Brown-Forsythe test was used to examine homogeneity or equality of variance. For multiple comparisons, one-way ANOVA, followed by Bonferroni post hoc tests, was used (GraphPad Prism 6.0, GraphPad Software Inc., San Diego, CA, USA). Statistical significance was set at the level of $p<0.05$.

Data availability. The authors declare that the data supporting the findings of this study are available within the paper and from the authors on request. Gene expression raw data that support the findings of this study have been deposited in Gene Expression Omnibus (GEO) with the accession number GSE101569.

Received: 2 February 2018 Accepted: 23 April 2018

Published online: 23 May 2018

\section{References}

1. Porcar, M. \& Peretó, J. Nature versus design: synthetic biology or how to build a biological non-machine. Integr. Biol. (Camb.) 8, 451-455 (2016).

2. Croxford, A. L., Mair, F. \& Becher, B. IL-23: one cytokine in control of autoimmunity. Eur. J. Immunol. 42, 2263-2273 (2012).

3. Stuhlmann-Laeisz, C. et al. Forced dimerization of gp130 leads to constitutive STAT3 activation, cytokine independent growth and blockade of differentiation of embryonic stem cells. Mol. Biol. Cell 17, 2986-2995 (2006).

4. Suthaus, J. et al. Forced homo- and heterodimerization of all gp130-type receptor complexes leads to constitutive ligand-independent signaling and cytokine-independent growth. Mol. Biol. Cell 21, 2797-2807 (2010).

5. Rebouissou, S. et al. Frequent in-frame somatic deletions activate gp130 in inflammatory hepatocellular tumours. Nature 457, 200-204 (2009).

6. Gerhartz, C. et al. Differential activation of acute phase response factor/STAT3 and STAT1 via the cytoplasmic domain of the interleukin 6 signal transducer gp130. I. Definition of a novel phosphotyrosine motif mediating STAT1 activation. J. Biol. Chem. 271, 12991-12998 (1996).

7. Spencer, D. M., Wandless, T. J., Schreiber, S. L. \& Crabtree, G. R. Controlling signal transduction with synthetic ligands. Science 262, 1019-1024 (1993).

8. Zhou, X. et al. Inducible caspase-9 suicide gene controls adverse effects from alloreplete $\mathrm{T}$ cells after haploidentical stem cell transplantation. Blood 125, 4103-4113 (2015)

9. Kloss, C. C., Condomines, M., Cartellieri, M., Bachmann, M. \& Sadelain, M. Combinatorial antigen recognition with balanced signaling promotes selective tumor eradication by engineered T cells. Nat. Biotechnol. 31, 71-75 (2013).

10. Krause, A. et al. Antigen-dependent CD28 signaling selectively enhances survival and proliferation in genetically modified activated human primary $\mathrm{T}$ lymphocytes. J. Exp. Med. 188, 619-626 (1998).

11. Prosser, M. E., Brown, C. E., Shami, A. F., Forman, S. J. \& Jensen, M. C. Tumor PD-L1 co-stimulates primary human CD8 $(+)$ cytotoxic T cells modified to express a PD1:CD28 chimeric receptor. Mol. Immunol. 51, 263-272 (2012).

12. Roybal, K. T. et al. Precision tumor recognition by $\mathrm{T}$ cells with combinatorial antigen-sensing circuits. Cell 164, 770-779 (2016).

13. Fedorov, V. D., Themeli, M. \& Sadelain, M. PD-1- and CTLA-4-based inhibitory chimeric antigen receptors (iCARs) divert off-target immunotherapy responses. Sci. Transl. Med. 5, 215ra172 (2013).

14. Fridy, P. C. et al. A robust pipeline for rapid production of versatile nanobody repertoires. Nat. Methods 12, 1253-1260 (2014).

15. Rothbauer, U. et al. A versatile nanotrap for biochemical and functional studies with fluorescent fusion proteins. Mol. Cell. Proteom. 7, 282-289 (2008).

16. Wesolowski, J. et al. Single domain antibodies: promising experimental and therapeutic tools in infection and immunity. Med. Microbiol. Immunol. 198, 157-174 (2009)

17. Schmitz, J., Weissenbach, M., Haan, S., Heinrich, P. C. \& Schaper, F. SOCS3 exerts its inhibitory function on interleukin-6 signal transduction through the SHP2 recruitment site of gp130. J. Biol. Chem. 275, 12848-12856 (2000).

18. Floss, D. M. et al. Identification of canonical tyrosine-dependent and noncanonical tyrosine-independent STAT3 activation sites in the intracellular domain of the interleukin 23 receptor. J. Biol. Chem. 288, 19386-19400 (2013).

19. Garbers, C. et al. Plasticity and cross-talk of interleukin 6-type cytokines. Cytokine Growth Factor Rev. 23, 85-97 (2012).

20. Floss, D. et al. Defining the functional binding sites of interleukin 12 receptor $\beta 1$ and interleukin 23 receptor to Janus kinases. Mol. Biol. Cell 27, 2301-2316 (2016).

21. Murray, P. J. The JAK-STAT signaling pathway: input and output integration. J. Immunol. 178, 2623-2629 (2007).

22. Wang, X., Lupardus, P., Laporte, S. \& Garcia, K. Structural biology of shared cytokine receptors. Annu. Rev. Immunol. 27, 29-60 (2009).

23. Yamanaka, Y., Nakajima, K., Fukada, T., Hibi, M. \& Hirano, T. Differentiation and growth arrest signals are generated through the cytoplasmic region of gp130 that is essential for Stat3 activation. EMBO J. 15, 1557-1565 (1996).

24. Okabe, M., Ikawa, M., Kominami, K., Nakanishi, T. \& Nishimune, Y. 'Green mice' as a source of ubiquitous green cells. FEBS Lett. 407, 313-319 (1997).

25. Fink, D. et al. Ubiquitous expression of the monomeric red fluorescent protein mCherry in transgenic mice. Genesis 48, 723-729 (2010).

26. Floss, D., Schröder, J., Franke, M. \& Scheller, J. Insights into IL-23 biology: From structure to function. Cytokine Growth Factor Rev. 26, 569-578 (2015)

27. Eulenfeld, R. et al. Interleukin-6 signalling: more than Jaks and STATs. Eur. J. Cell Biol. 91, 486-495 (2011).

28. Ghoreschi, K., Laurence, A. \& O'Shea, J. J. Janus kinases in immune cell signaling. Immunol. Rev. 228, 273-287 (2009).

29. Kim, A. et al. Functional selectivity in cytokine signaling revealed through a pathogenic EPO mutation. Cell 168, 1053-1064 (2017). 
30. Hummel, T. M. et al. Synthetic deletion of the interleukin 23 receptor (IL-23R) stalk region led to autonomous IL-23R homodimerization and activation. Mol. Cell. Biol. 37, e00014-17 (2017).

31. Schröder, J. et al. Non-canonical Interleukin 23 receptor complex assembly: $\mathrm{P} 40$ protein recruits interleukin 12 receptor $\beta 1$ via site ii and induces p19/ interleukin 23 receptor interaction via site III. J. Biol. Chem. 290, 359-370 (2015).

32. Leibly, D. J. et al. A suite of engineered GFP molecules for oligomeric scaffolding. Structure 23, 1754-1768 (2015).

33. Kim, Y. E., Kim, Y. N., Kim, J. A., Kim, H. M. \& Jung, Y. Green fluorescent protein nanopolygons as monodisperse supramolecular assemblies of functional proteins with defined valency. Nat. Commun. 6, 7134 (2015).

34. Janda, C. Y. et al. Surrogate Wnt agonists that phenocopy canonical Wnt and beta-catenin signalling. Nature 545, 234-237 (2017).

35. Moraga, I. et al. Synthekines are surrogate cytokine and growth factor agonists that compel signaling through non-natural receptor dimers. eLife 6, e22882 (2017).

36. Pawson, T. Protein modules and signalling networks. Nature 373, 573-580 (1995).

37. Kelly, J. D. et al. Platelet-derived growth factor (PDGF) stimulates PDGF receptor subunit dimerization and intersubunit trans-phosphorylation. J. Biol. Chem. 266, 8987-8992 (1991).

38. Lai, C. C., Henningson, C. \& DiMaio, D. Bovine papillomavirus E5 protein induces oligomerization and trans-phosphorylation of the platelet-derived growth factor beta receptor. Proc. Natl Acad. Sci. USA 95, 15241-15246 (1998).

39. Li, Z., Mei, Y., Liu, X. \& Zhou, M. Neuregulin-1 only induces transphosphorylation between ErbB receptor heterodimer partners. Cell Signal. 19, 466-471 (2007).

40. Luwor, R. B. et al. The tumor-specific de2-7 epidermal growth factor receptor (EGFR) promotes cells survival and heterodimerizes with the wild-type EGFR. Oncogene 23, 6095-6104 (2004).

41. Qian, X., Dougall, W. C., Fei, Z. \& Greene, M. I. Intermolecular association and trans-phosphorylation of different neu-kinase forms permit $\mathrm{SH} 2$ dependent signaling and oncogenic transformation. Oncogene 10, 211-219 (1995).

42. Gearing, D. et al. Proliferative responses and binding properties of hematopoietic cells transfected with low-affinity receptors for leukemia inhibitory factor, oncostatin $\mathrm{M}$, and ciliary neurotrophic factor. Proc. Natl Acad. Sci. USA 91, 1119-1123 (1994).

43. Ketteler, R., Glaser, S., Sandra, O., Martens, U. M. \& Klingmuller, U. Enhanced transgene expression in primitive hematopoietic progenitor cells and embryonic stem cells efficiently transduced by optimized retroviral hybrid vectors. Gene Ther. 9, 477-487 (2002).

44. Fischer, M. et al. A bioactive designer cytokine for human hematopoietic progenitor cell expansion. Nat. Biotechnol. 15, 145-145 (1997).

45. Fang, J. et al. Stable antibody expression at therapeutic levels using the $2 \mathrm{~A}$ peptide. Nat. Biotechnol. 23, 584-590 (2005).

46. Genové, G., Glick, B. S. \& Barth, A. L. Brighter reporter genes from multimerized fluorescent proteins. Biotechniques 39, 816-818 (2005).

47. R: A Language and Environment for Statistical Computing, Reference Index Version 2.2.1 (R Foundation for Statistical Computing, Vienna, Austria, 2005).
48. Rainer, J., Sanchez-Cabo, F., Stocker, G., Sturn, A. \& Trajanoski, Z. CARMAweb: comprehensive R- and bioconductor-based web service for microarray data analysis. Nucl. Acids Res. 34, W498-W503 (2006).

49. Kim, M. J. \& Ahituv, N. The hydrodynamic tail vein assay as a tool for the study of liver promoters and enhancers. Methods Mol. Biol. (Clifton, N. J.) 1015, 279-289 (2013).

\section{Acknowledgements}

We thank Petra Oprée for assistance. This work was funded by grants from the Deutsche Forschungsgemeinschaft (RTG1949, SFB974 and SFB 1116).

\section{Author contributions}

E.E., A.S. conducted most of the experiments and analyzed the data. M.F., R.C., A.L., P.B., J.M.M., and D.M.F. supported cloning, recombinant protein expression and cell culture experiments. H.X., P.A.L. performed the in vivo mice study. C.B., B.K., H.A.H. performed the microarray study. All authors helped writing the paper. J.S. designed the study, analyzed the data, and wrote the paper.

\section{Additional information}

Supplementary Information accompanies this paper at https://doi.org/10.1038/s41467018-04454-8.

Competing interests: The authors declare no competing interests.

Reprints and permission information is available online at http://npg.nature.com/ reprintsandpermissions/

Publisher's note: Springer Nature remains neutral with regard to jurisdictional claims in published maps and institutional affiliations.

Open Access This article is licensed under a Creative Commons Attribution 4.0 International License, which permits use, sharing, adaptation, distribution and reproduction in any medium or format, as long as you give appropriate credit to the original author(s) and the source, provide a link to the Creative Commons license, and indicate if changes were made. The images or other third party material in this article are included in the article's Creative Commons license, unless indicated otherwise in a credit line to the material. If material is not included in the article's Creative Commons license and your intended use is not permitted by statutory regulation or exceeds the permitted use, you will need to obtain permission directly from the copyright holder. To view a copy of this license, visit http://creativecommons.org/ licenses/by/4.0/.

(C) The Author(s) 2018 